UNIVERSIDADE DE SÃO PAULO

ESCOLA DE ENFERMAGEM

SIOMARA TAVARES FERNANDES YAMAGUTI

RITMO DIURNO DE SECREÇÃO DE CORTISOL E CARGA ALOSTÁTICA EM PROFISSIONAIS DE ENFERMAGEM

SÃO PAULO

2015 


\section{RITMO DIURNO DE SECREÇÃO DE CORTISOL E CARGA ALOSTÁTICA EM PROFISSIONAIS DE ENFERMAGEM}

Dissertação apresentada ao Programa de PósGraduação em Enfermagem na Saúde do Adulto da Universidade de São Paulo para obtenção do título de Mestre em Enfermagem.

Área de concentração: Enfermagem na Saúde do Adulto

Orientadora: Prof $^{a}$ Dr $^{\mathrm{a}}$ Juliana Nery de Souza Talarico 
AUTORIZO A REPRODUÇÃO E DIVULGAÇÃO TOTAL OU PARCIAL DESTE TRABALHO, POR QUALQUER MEIO CONVENCIONAL OU ELETRÔNICO, PARA FINS DE ESTUDO E PESQUISA, DESDE QUE CITADA A FONTE.

Assinatura:

Data:

Catalogação na Publicação (CIP)

Biblioteca "Wanda de Aguiar Horta"

Escola de Enfermagem da Universidade de São Paulo

Yamaguti, Siomara Tavares Fernandes

Ritmo diurno de secreção de cortisol e carga alostática em profissionais de enfermagem. -- São Paulo, 2015.

$92 \mathrm{p}$.

Dissertação (Mestrado) - Escola de Enfermagem da Universidade de São Paulo.

Orientadora: Profa. Dra. Juliana Nery de Souza Talarico

Área de concentração: Enfermagem na Saúde do Adulto

1. Estresse. 2. Cortisol. 3. Enfermeiros. I. Título. 


\section{FOLHA DE APROVAÇÃO}

Nome: Siomara Tavares Fernandes Yamaguti

Título: Ritmo diurno de secreção de cortisol e carga alostática em profissionais de enfermagem

Dissertação apresentada ao Programa de Enfermagem na Saúde do Adulto da Escola de Enfermagem da Universidade de São Paulo para obtenção do título de Mestre em Enfermagem.

Aprovado em:

\section{BANCA EXAMINADORA}

Prof. Dr. Instituição:

Julgamento: Assinatura:

Prof. Dr. Instituição:

Julgamento: Assinatura:

Prof. Dr. Instituição:

Julgamento: Assinatura: 


\section{DEDICATÓRIA}

A Deus por me amparar nos momentos dificeis, me dar força interior para superar as dificuldades, mostrar o caminho nas horas incertas e me suprir em todas as minhas necessidades.

Aos meus pais, pelo exemplo de vida e por sempre me ensinarem a lutar por meus sonhos.

Ao meu amor Paulo que está presente em todos os momentos da minha vida, me apoiando e incentivando nesta trajetória. 


\section{AGRADECIMENTOS}

A minha querida orientadora, Juliana Nery, pela convivência e amizade, por acreditar em mim e ter sido minha parceira acompanhando meu processo de formação.

Aos meus irmãos Eliane e Homero pelo incentivo mesmo estando longe sempre estiveram muito presentes em minha vida.

A toda minha família, a qual amo muito, pelo carinho e incentivo.

À Dra Bernardete Weber que sempre incentivou e apoiou os meus estudos.

À Prof ${ }^{a}$ Dr $^{a}$ Ana Lúcia Siqueira Costa, Prof ${ }^{a}$ Dr $^{a}$ Dora Maria Grassi Kassisse e Prof ${ }^{a}$ Dr $^{a}$ Maria Lucia do Carmo Cruz Robazzi pela pertinência das sugestões no exame de qualificação, apoio e atenção.

À Amanda Roca Blasques de Mendonça, Daniela Coelho e Amanda Luiz Machado, muito obrigada pela ajuda e dedicação.

Aos amigos André Luiz Peres Nicola, Ana Paula Lima da Silva e Aline Talita dos Santos pela amizade e apoio.

Aos colegas de trabalho pelo incentivo e carinho.

Aos amigos que tive o privilégio de conhecer nesta caminhada meu carinho e amizade sinceros.

A todos os professores que participaram da minha formação acadêmica ao longo destes anos.

Ao Hospital Universitário da Universidade de São Paulo pela possibilidade de desenvolvimento dessa pesquisa.

À equipe de enfermagem do Hospital Universitário, que tornaram possível a realização dessa pesquisa.

Ao PROESA pela oportunidade de desenvolver este projeto.

À FAPESP pelo apoio financeiro. 


\section{RESUMO}

Yamaguti STF. Ritmo diurno de secreção de cortisol e carga alostática em profissionais de enfermagem [Dissertação]. São Paulo: Escola de Enfermagem, Universidade de São Paulo; 2015.

Introdução: A vulnerabilidade dos profissionais de enfermagem ao estresse está associada à exposição crônica aos estressores cotidianos de trabalho e, consequentemente, aos efeitos cumulativos dos mediadores primários e secundários do estresse. Embora vários estudos tenham relatado o elevado nível de estresse dos profissionais de enfermagem, pouco se sabe a respeito das implicações biológicas do estresse no trabalho, expressas na carga alostática e no ritmo de secreção dos hormônios de cortisol um dos principais hormônios do estresse. Isto particularmente é importante visto que a carga alostática aumenta o risco do indivíduo desenvolver transtornos relacionados ao estresse como síndromes cardiovasculares, metabólicas, endócrinas, emocionais e cognitivas. Neste sentido, questiona-se se os profissionais de enfermagem apresentam sobrecarga do sistema adaptativo de reação do estresse (carga alostática), bem como alterações no ritmo de secreção de cortisol (hiper ou hipocortisolemia) ao longo do dia e o risco para o desenvolvimento de doenças relacionadas ao estresse. Objetivo: Descrever a frequência de profissionais de enfermagem com carga alostática elevada e ritmo atípico de secreção de cortisol. Analisar se a carga alostática elevada está associada ao ritmo atípico de secreção de cortisol. Método: Foram incluídos 142 profissionais de enfermagem do turno diurno randomicamente selecionados, alocados nas unidades ambulatório, clínica médica, clínica cirúrgica, centro cirúrgico, pronto socorro infantil e adulto, unidade de terapia intensiva adulto e pediátrica de um hospital universitário. Para avaliação do padrão diurno de secreção de cortisol foram coletadas amostras de saliva em dois dias úteis consecutivos de trabalho e, para a análise dos biomarcadores foram coletadas, em um único dia, amostras de sangue de todos os participantes, bem como, verificada sua pressão arterial e medidas antropométricas. A carga alostática foi analisada por mediadores neuroendócrinos, metabólicos, cardiovasculares e imunológicos. Os dados foram armazenados e analisados utilizando o programa estatístico SPSS versão 14.0 e o nível de significância adotado foi de 5\%. Resultados: $31 \%$ dos profissionais de enfermagem apresentaram padrão atípico (inconsistente ou "flat") de secreção de cortisol e 47,2\% carga alostática elevada. Não houve associação entre o ritmo de secreção de cortisol e a carga alostática. Conclusão: Quase metade dos profissionais de enfermagem apresentaram sinais de 
desgaste do sistema biológico regulador da resposta de estresse, sugerindo que o trabalho possa estar associado a esta sobrecarga e destacando a vulnerabilidade destes trabalhadores ao desenvolvimento de doenças relacionadas ao estresse.

PALAVRAS-CHAVE: estresse, eixo hipotálamo-pituitária-adrenal, cortisol, carga alostática, profissionais de enfermagem. 


\begin{abstract}
Yamaguti STF. Diurnal rhythm of cortisol secretion and allostatic load among nursing professional. São Paulo: Escola de Enfermagem, Universidade de São Paulo; 2015.
\end{abstract}

Background: The vulnerability of nursing professionals to stress is associated with chronic exposure to everyday stressors and, therefore, with the cumulative effects of primary and secondary stress mediators. Despite the fact that several studies have reported the high stress level of nursing professionals, little is known about the biological implications of stress at work, expressed in the allostatic load and in the rhythm of cortisol secretion, one of the main hormones of stress. This is especially important since the allostatic load increases the risk of an individual to develop stress-related disorders like cardiovascular syndromes, metabolic, endocrine, cognitive and emotional. In this aspect, there are questions whether the nursing professionals present overload on the stress adaptive reaction system (allostatic load), as well as, changes in the rhythm of cortisol secretion (hyper or hypocortisolemia) throughout the day and the risk of developing stress-related diseases. Objective: To describe the frequency of nursing professionals with high allostatic load and atypical rhythm of cortisol secretion. To analyze whether the high allostatic load is associated with atypical rhythm of cortisol secretion. Methods: We included 142 nursing professionals day shift randomly selected, allocated in the outpatient units, medical clinic, surgical clinic, surgery, children and adults emergency room and adult intensive care unit in a pediatric teaching hospital. To evaluate the daytime pattern of cortisol secretion, saliva samples were collected in two work day and, for the analysis of biomarkers, were collected in a single day, blood samples from all participants, as well as, checked his blood pressure and anthropometric measurements. Allostatic load was analized by neuroendocrine, metabolic, cardiovascular and immune mediators. The data was stored and analyzed using the program SPSS version 14.0 and the statistical significance level adopted was $5 \%$. Results: $31 \%$ of nursing professionals showed atypical pattern (inconsistent or "flat") of secretion of cortisol and $47.2 \%$ showed high allostatic load. There was no association between the rate of secretion of cortisol and the allostatic load. Conclusion: Nearly half of nursing professionals showed signs of wear in the biological system stress response regulator, suggesting that the job can be associated with this overload and highlighting the vulnerability of these workers to the development of stress-related diseases.

KEYWORDS: stress, hypothalamic-pituitary-adrenal glands, cortisol, allostatic load, nursing professionals. 


\section{LISTA DE FIGURAS}

Figura 1 Reação alostática normal (A), exposição a eventos estressantes 22 repetitivos (B), ausência de adaptação ao estresse crônico (C), ausência de recuperação ao funcionamento homeostático (D) e reações inadequadas decorrentes do estresse crônico (E). Fonte original: McEwen, 1998; adaptado

Figura 2 Ritmo circadiano de secreção de cortisol em humanos. Fonte: 36 Lupien et al, 2007; adaptado

$\begin{array}{lll}\text { Figura } 3 & \text { Procedimento de coleta de saliva no salivette } & 37\end{array}$

$\begin{array}{lll}\text { Figura } 4 & \text { Medical event monitoring system, (mens®) } & 37\end{array}$

Figura 5 Representação esquemática do procedimento de coleta de dados 42

Figura 6 Ritmo de secreção de cortisol ao longo do dia na amostra de 49 profissionais de enfermagem do Hospital Universitário da USP. São Paulo, 2015

Figura 7 Ritmo de secreção de cortisol ao longo do dia e o sexo na amostra 50 de profissionais de enfermagem do Hospital Universitário da USP. São Paulo, 2015

Figura 8 Classificação da amostra de profissionais de enfermagem do 51 Hospital Universitário da USP segundo padrão de secreção de cortisol. São Paulo, 2015

Figura 9 Média da concentração de cortisol ao longo do dia segundo padrão de secreção na amostra de profissionais de enfermagem do Hospital Universitário da USP. São Paulo, 2015

Figura 10 Padrão de secreção de cortisol segundo tempo na profissão e tempo de trabalho no Hospital Universitário (A), categoria profissional (B), turno de trabalho (C) e Unidade de atendimento (D)

Figura 11 Intensidade da carga alostática segundo categoria profissional (A), turno de trabalho (B) e Unidade de atendimento (C)

Figura 12 Porcentagem do padrão de secreção cortisol segundo intensidade da 56 carga alostática da amostra de profissionais de enfermagem do Hospital Universitário. São Paulo, 2015

Figura 13 Ritmo de secreção de cortisol ao longo do dia em relação à 57 intensidade da carga alostática 


\section{LISTA DE TABELAS}

Tabela 1 Caracterização da amostra de profissionais de enfermagem do 46 Hospital Universitário da USP segundo idade e escolaridade. São Paulo, 2015.

Tabela 2 Caracterização sociodemográfica da amostra de profissionais de 46 enfermagem do Hospital Universitário da USP segundo sexo, estado civil e nível socioeconômico. São Paulo, 2015.

Tabela 3 Distribuição da amostra de profissionais de enfermagem do Hospital 47 Universitário da USP segundo antecedentes pessoais e uso de medicações. São Paulo, 2015

Tabela 4 Classificação da amostra de profissionais de enfermagem segundo carga horária semanal de trabalho, tempo de trabalho na profissão e tempo de trabalho no Hospital Universitário da USP. São Paulo, 2015

Tabela 5 Classificação da amostra de profissionais de enfermagem segundo a 48 categoria profissional e alocação nas unidades de atendimento do Hospital Universitário da USP. São Paulo, 2015

Tabela 6 Classificação da amostra de profissionais de enfermagem alocados 48 em unidades críticas e não críticas no Hospital Universitário da USP. São Paulo, 2015

Tabela 7 Padrão de distribuição dos biomarcadores analisados para o cálculo 52 do índice de carga alostática.

Valores de referência dos biomarcadores analisados com unidades do

Tabela 8 sistema nacional e sistema internacional e os respectivos valores de 92 conversão. 


\section{LISTA DE SIGLAS}

ACTH Hormônio adrenocorticotrófico

ANA American Nursing Association

AUC Área sob a curva

CAR Cortisol Awakening Response

CC Centro Cirúrgico

CLC Clinica Cirúrgica

CM Clinica Médica

COFEN Conselho Federal de Enfermagem

CRH Hormônio corticotropina

CGB Globulina ligadora de corticosteróide

DHEA Dehidroepiandrosterona

DHEA-S Dehidroepiandrosterona sulfatada

EE-USP Escola de Enfermagem da Universidade de São Paulo

FAPESP Fundação de Amparo à Pesquisa do Estado de São Paulo

G/L Mililitros

HPA Eixo hipotálamo-pituitária-adrenal

HU Hospital Universitário

ICA Índice de Carga Alostática

IPEA Instituto de Pesquisa Econômica Aplicada

MEMS Medical Event Monitoring System

mmHg Milímetros de mercúrio

mmol/L Milimoles por litro

NIOSH National Institute for Occupational Safety and Health

$\mathbf{n m o l} / \mathbf{L} \quad$ Nanomol por litro

$\mathbf{u g} / \mathbf{d L} \quad$ Micrograma por decilitro

PAD Pressão arterial sistólica

PAS Pressão arterial sistólica

PSA Pronto Socorro adulto 
PSI Pronto Socorro Infantil

p.ex. Por exemplo

SGA Síndrome Geral de Adaptação

SMS Short Message Service

SI Sistema internacional

SN Sistema Nacional

SNA Sistema nervoso autônomico simpático

TCLE Termo de Consentimento Livre e Esclarecido

USB Universal Serial Bus

USP Universidade de São Paulo

UTI - A Unidade de Terapia Intensiva adulto

UTI - P Unidade de Terapia Pediátrica 


\section{SUMÁRIO}

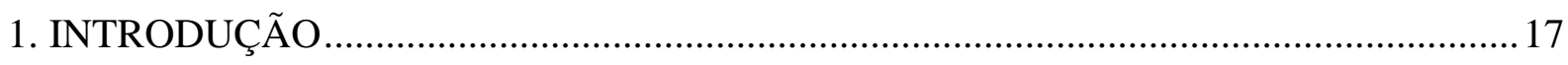

1.1 REVELANDO O PROBLEMA DE PESQUISA ................................................. 17

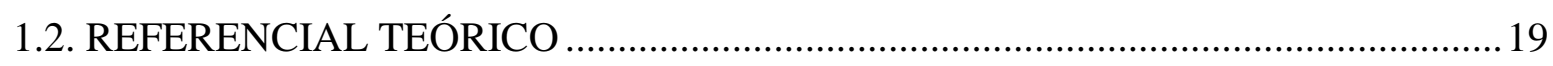

1.2.1. Teoria da resposta de estresse: alostase e carga alostática .................................. 19

1.3 Resposta fisiológica do estresse: da alostase à carga alostática..................................21

1.4 Enfermagem e estresse: porque a enfermagem é uma profissão estressante? ................24

1.5 Impacto biológico do estresse crônico nos profissionais de enfermagem ......................25

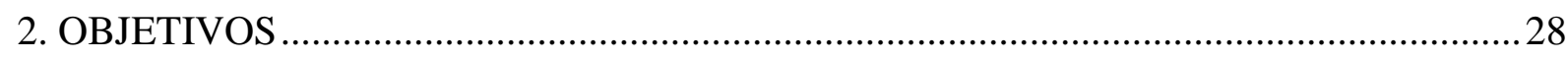







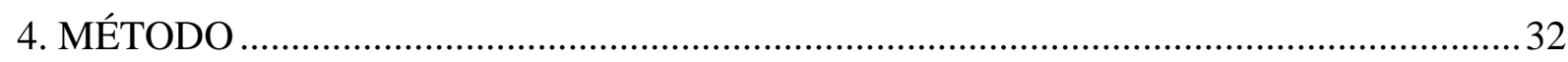

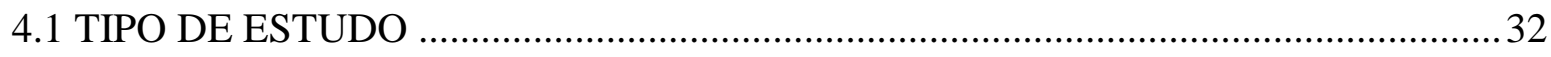



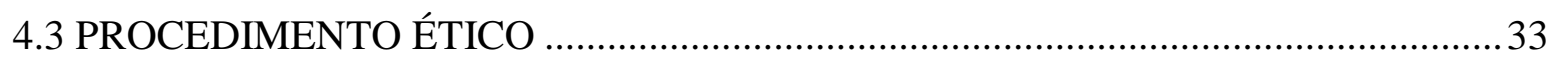

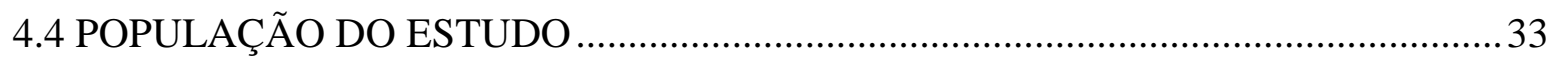

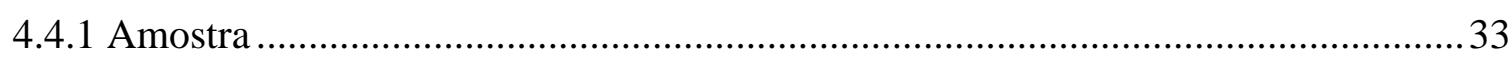



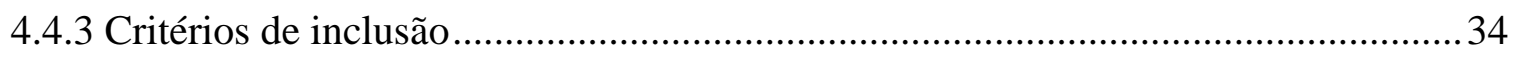

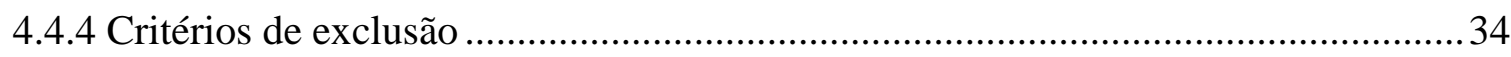

4.5. VARIÁVEIS DE INTERESSE E MÉTODO DE ANÁLISE ..................................... 35







5.1 CARACTERIZAÇÃO SOCIODEMOGRÁFICA E ANTECEDENTES DE SAÚDE: 46 5.2 CARACTERIZAÇÃO DA AMOSTRA QUANTO AO REGIME DE TRABALHO E

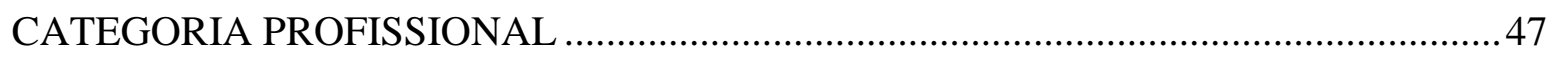


5.3 CARACTERIZAÇÃO DO RITMO E PADRÃO DE SECREÇÃO CORTISOL.......... 48

5.4 CARACTERIZAÇÃO DA CARGA ALOSTÁTICA …..............................................52

5.5 ASSOCIAÇÃO ENTRE AS CARACTERÍSTICAS DE REGIME DE TRABALHO E O PADRÃO DE SECREÇÃO DE CORTISOL E A CARGA ALOSTÁTICA....................53

5.6 ASSOCIAÇÃO ENTRE O PADRÃO DE SECRREÇÃO DE CORTISOL E CARGA

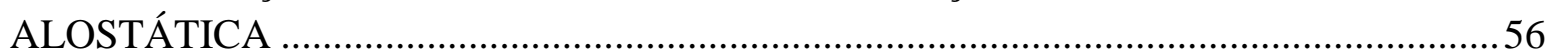

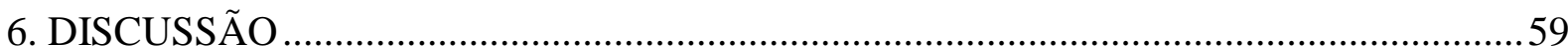

6.1 CARACTERIZAÇÃO SOCIODEMOGRÁFICA DA AMOSTRA ..............................59

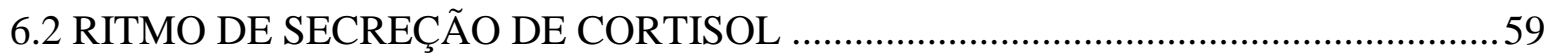

6.3 CARGA ALOSTÁTICA NOS PROFISSIONAIS DE ENFERMAGEM......................63

6.4 INFLUÊNCIAS DAS CARACTERÍSTICAS DO REGIME DE TRABALHO NO

PADRÃO DE SECREÇÃO DE CORTISOL E NA CARGA ALOSTÁTICA.....................64

6.5 ASSOCIAÇÃO ENTRE INTENSIDADE DA CARGA ALOSTÁTICA E PADRÃO

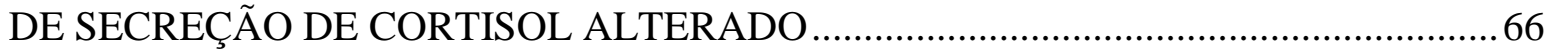

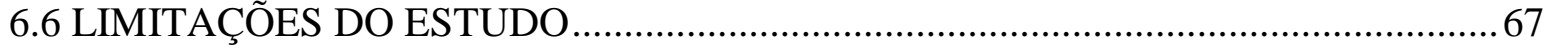

7. CONCLUSÃO

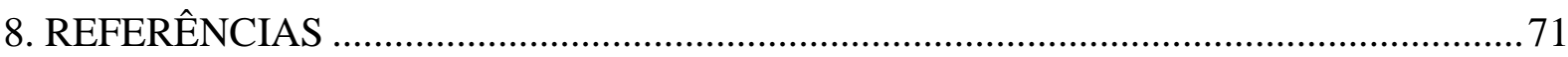

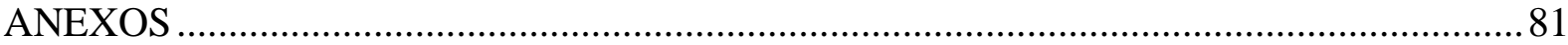

ANEXO A - TERMO DE CONSENTIMENTO LIVRE E ESCLARECIDO ........................ 81

ANEXO B - QUESTIONÁRIO SÓCIO-DEMOGRÁFICO DE IDENTIFICAÇÃO .............83

ANEXO C - ORIENTAÇÕES PARA A COLETA DE SALIVA …........................................ 85

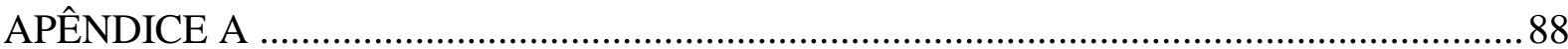

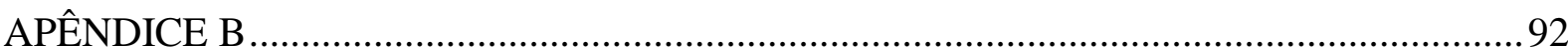


INTRODUÇÃO 


\section{INTRODUÇÃO}

\subsection{REVELANDO O PROBLEMA DE PESQUISA}

Várias tem sido as adversidades vividas pelos profissionais da saúde frente à criação de novas tecnologias e a produção acelerada de conhecimento e informação. As atuais exigências sociais têm exigido do indivíduo enfrentamento constante de situações novas e imprevisíveis, que por sua vez, desencadeiam reações biológicas e comportamentais de resolução ou controle que muitas vezes ultrapassam o potencial adaptativo do sistema orgânico, comprometendo seu funcionamento e colocando o indivíduo em risco para o adoecimento ${ }^{1}$.

Em seu cotidiano, os profissionais de enfermagem vivenciam estas adversidades e exigências sociais no relacionamento interpessoal e profissional, no ambiente laboral, na manipulação de equipamentos e sistemas com tecnologia nova e avançada de cuidado, na implantação de protocolos assistenciais e nas mudanças culturais dentro da organização de trabalho. Todas estas situações exigem adaptação e por ser caráter novo, muitas vezes imprevisível, com pouca capacidade de controle e com elevado teor de avaliação social estimulam reações fisiológicas de estresse na tentativa de solucionar ou controlar o evento em questão $^{2,3}$.

A Organização Internacional do Trabalho considera a enfermagem como uma das profissões mais desgastantes devido à carga horária de trabalho, o tipo de trabalho, multiempregos, tomada de decisões, bem como os riscos biológicos implicados na profissão ${ }^{4}$.

Em profissionais que atuam em unidades de atendimento crítico, como as unidades de terapia intensiva, estima-se que $67 \%$ dos enfermeiros assistenciais apresentam sinais de desgaste físico e emocional ${ }^{5}$.

A vulnerabilidade dos profissionais de enfermagem ao estresse está associada à exposição crônica aos estressores cotidianos de trabalho e, consequentemente, aos efeitos cumulativos dos mediadores primários e secundários do estresse ${ }^{6,7}$. Estes mediadores são liberados mediante a reação fisiológica de reação do estresse (reação alostática). Entretanto, a 
exposição prolongada e repetitiva aos efeitos destes mediadores podem sobrecarregar a reação alostática (carga alostática) tornando esses indivíduos vulneráveis ao adoecimento.

Diversos estudos têm descrito o elevado nível de estresse dos profissionais de enfermagem avaliado a partir da percepção do sujeito sobre sinais e sintomas comportamentais e emocionais relacionados aos estressores cotidianos de trabalho ${ }^{2,8}$. Entretanto, pouco se sabe a respeito das implicações biológicas do estresse na saúde do trabalhador, expressas na carga alostática e no ritmo de secreção de cortisol, um dos principais hormônios do estresse.

Neste sentido, questiona-se se os profissionais de enfermagem apresentam sobrecarga do sistema adaptativo de reação do estresse (carga alostática), bem como alterações no ritmo de secreção de cortisol (hiper ou hipocortisolemia) ao longo do dia.

Este questionamento é relevante, dado que a carga alostática aumenta o risco do indivíduo desenvolver transtornos relacionados ao estresse como síndromes cardiovasculares, metabólicas, endócrinas, emocionais e cognitivas ${ }^{2}$.

A identificação de profissionais em situação de carga alostática e alteração no ritmo diurno de secreção de cortisol permitirá identificar analisar como os desgastes físicos e emocionais destes trabalhadores, tão extensamente descritos na literatura, expressam-se no funcionamento do organismo e no risco para o desenvolvimento de doenças relacionadas ao estresse. 


\subsection{REFERENCIAL TEÓRICO}

\subsubsection{Teoria da resposta de estresse: alostase e carga alostática}

As diferentes orientações teóricas que explicam o estresse estão categorizadas em três principais eixos de conceituação: estresse baseado na resposta, baseado no estímulo ou baseado numa abordagem transacional que considera a interação do indivíduo com o meio ${ }^{9}$. Considerando a lacuna de conhecimento existente nas implicações biológicas do estresse crônico nos profissionais de enfermagem, no presente estudo, abordamos o referencial teórico do estresse baseado na resposta. Entretanto, é necessário destacar que o estresse é um construto multidimensional e que as demais correntes teóricas permitem a análise ampliada e transacional do fenômeno estresse.

Historicamente a teoria do estresse como resposta foi proposta por Hans Selye na década de 30 do século passado, que definiu o estresse como uma "resposta não específica do organismo a qualquer agente nocivo". Selye propôs que a resposta fisiológica do estresse é sempre a mesma independentemente do estímulo e que o corpo apresentava uma reserva adaptativa finita que se esgotava a medida que a exposição aos agentes nocivos se tornava prolongada. Em seus estudos, Selye constatou que o estresse produzia uma variedade de reações de defesa e adaptação frente ao agente estressor e ao analisar os impactos fisiológicas do estresse, ele as denominou de "Síndrome Geral de Adaptação" (SGA), que cursava em

fases cronologicamente definidas: alarme, resistência e exaustão ${ }^{10}$. Entretanto, ao longo de sua trajetória científica, o próprio Selye contribuiu para redefinição da teoria do estresse como resposta apresentando pontos centrais que se mantém até a atualidade. Dentre eles, destaca-se que, na perspectiva do estresse como resposta, que o estresse é uma resposta adaptativa e, portanto, o estresse por si próprio não é algo ruim, mas que o estresse pode ser nocivo se mantido prolongadamente e que o organismo possue estratégias adaptativas de enfrentamento (coping) a situação de estresse na tentativa modular seus os efeitos nocivos. Selye, em um de seus últimos trabalhos, também introduziu a ideia de que esta reação de defesa do corpo quando se torna excessiva poderia provocar o adoecimento por doenças cardiovasculares, imunológicas e mentais ${ }^{11}$.

Mason, outro teorista do estresse como resposta, introduziu o conceito de que o processo de enfrentamento (coping) modula a resposta neuroendócrina de estresse e que esta reposta variava em função da característica do estímulo. A grande contribuição de Mason foi a definição de que não apenas agentes nocivos, mas que determinadas características de 
natureza psicológica modulavam a resposta de estresse. Com seus experimentos em humanos, Mason demonstrou que características como novidade, imprevisibilidade e senso de controle são capazes de estimular a reação de estresse com a secreção dos hormônios neuroendócrinos e de ação adrenérgica ${ }^{12}$. Mais recentemente, uma revisão sistemática da literatura com metanálise incluiu o quarto fator psicológico determinante da resposta de estresse: o componente social avaliativo ou ameaça à auto-identidade ${ }^{13}$.

Ainda baseado na teoria do estresse como resposta, McEwen, Mendelson (1993) e Sterling, Eyer (1988), complementaram o conceito de estresse defendido por Selye, introduzindo a ideia de que a manutenção da estabilidade fisiológica do organismo frente às demandas de um agente estressor é alcançada a partir de um processo biológico dinâmico e interrelacional, intitulado alostase, que altera os parâmetros homeostáticos de normalidade para parâmetros que possam atender apropriadamente às exigências necessárias para promover a adaptação do organismo ao evento estressor ${ }^{14,15}$. Por exemplo, para garantir a manutenção do equilíbrio fisiológico frente a exposição de um indivíduo a falar em público, os parâmetros de normalidade da pressão arterial e da frequência cardíaca se alteram mediante à demanda de maior oxigenação cerebral e energia para o funcionamento adequado das estruturas relacionadas à memória e à atenção necessária para uma boa apresentação. Os diferentes sistemas do organismo humano devem e precisam sofrer variações em seus parâmetros naturais de funcionamento para responder apropriadamente às demandas crônicas de exposição ao estresse (p.ex.: "reprogramar" temporariamente os parâmetros sistêmicos para um novo valor de referência). Durante a alostase ou reação alostática, as funções fisiológicas do organismo são mobilizadas ou suprimidas frente ao evento estressor numa cascata de reações envolvendo estruturas cerebrais de controle da resposta de estresse e órgãos alvos de seus mediadores primários (cortisol e adrenalina) com a finalidade de manter a regulação do organismo. Assim, reação alostática é essencial para a adaptação, manutenção da homeostase e sobrevivência. Entretanto, sua ativação prolongada ou repetitiva pode desgastar esse sistema de proteção (carga alostática) e acelerar o processo de adoecimento.

Diante do exposto, a investigação dos efeitos negativos da exposição crônica e prolongada dos profissionais de enfermagem aos estressores do trabalho será realizada mediante a perspectiva de que o estresse se constitui uma resposta fisiológica do corpo a uma ameaça real (p.ex.: risco de morte) ou relativa (p. ex.: falta de funcionário) que, a partir de um processo biológico e dinâmico, reprograma os parâmetros de normalidade de funcionamento homeostático para adaptar o indivíduo às demandas decorrentes do evento estressor e que a 
manutenção prolongada e repetitiva desse processo pode desgastar esse próprio sistema de proteção (carga alostática), aumentando a vulnerabilidade do indivíduo ao adoecimento.

\subsection{Resposta fisiológica do estresse: da alostase à carga alostática}

A percepção da presença de um evento estressor desencadeia a reação aguda (ou de curto prazo) de estresse, caracterizada, inicialmente pela ativação do sistema nervoso autônomico simpático (SNA), que estimula a porção medular das glândulas adrenais a secretarem catecolaminas (adrenalina e noradrenalina), que agem principalmente no fígado e nos vasos sanguíneos ${ }^{12,13}$.

Além disso, a adrenalina alguns minutos após, ocorre a ativação do eixo hipotálamopituitária-adrenal (HPA) ${ }^{2,16}$, que estimula as glândulas localizadas no núcleo para ventricular do hipotálamo a secretarem o hormônio liberador de corticotropina (CRH). O CRH estimula a glândula pituitária anterior a liberar o hormônio adrenocorticotrófico (ACTH) que, por sua vez, chega ao córtex da glândula adrenal pela corrente sanguínea, estimulando a secreção de glicocorticoides (cortisol em humanos, corticosterona em animais) ${ }^{2,17}$.

A lipossolubilidade permite a passagem do cortisol pela barreira hemato-encefálica, garantindo seu acesso a estruturas cerebrais de regulação do eixo HPA. A interação do cortisol com seus receptores específicos localizados no hipocampo, amígdala e córtex préfrontal inibe o eixo HPA, num sistema de retroalimentação ou feedback negativo, permitindo a interrupção na secreção de cortisol ${ }^{18}$.

A adrenalina e o cortisol agem sobre receptores celulares de diferentes órgãos do corpo, alterando a atividade celular e a expressão gênica, levando a efeitos bifásicos (ativação ou inibição) e não lineares nos sistemas alvos (sistema cardiovascular, imunológico, neuroendócrino, metabólico e cerebral), de modo a adaptar o organismo às demandas exigidas pela situação estressora ${ }^{19}$. Juntamente com a adrenalina e o cortisol, seu antagonista (o hormônio dehidroepiandrosterona - DHEA) e citocinas pro e anti-inflamatórias (p. ex.: interleucina IL-6), representam os mediadores primários no sistema alostático da reação de curto prazo de estresse ${ }^{2,20}$. Uma vez cessado o estímulo estressor, esses mediadores alostáticos devem ser desativados ou inibidos para que essa cascata de efeitos seja interrompida e o sistema orgânico retorne a seu funcionamento normal (Figura 1A) ${ }^{2,20}$. 
Entretanto, a exposição repetitiva a eventos estressantes (Figura 1B), ou a ausência de adaptação do indivíduo a esta situação (Figura 1C), bem como a manutenção da ativação do sistema alostático que prolonga a exposição do indivíduo aos efeitos dos mediadores alostáticos, impedindo a recuperação à condição homeostática normal (Figura 1D) ${ }^{2,20}$. Sob estas condições, os sistemas biológicos subsidiários compensam a super/subprodução dos mediadores primários para manter o funcionamento químico, tissular e orgânico, produzindo uma reação inadequada de estresse (hiper ou hipocortisolemia, por exemplo) mediante eventos estressantes subsequentes (Figura 1E) ${ }^{2,20}$. Este estágio prodrômico é reconhecido como "efeito secundário", no qual parâmetros metabólicos (p.ex. insulina, glicose, colesterol total, colesterol HDL, triglicérides, depósito de gordura visceral), cardiovasculares (p.ex. pressão sistólica e diastólica) e imunológicos (p.exe.: fibrinogênio, proteína $\mathrm{C}$ reativa) atingem níveis subclínicos ${ }^{2,20}$. O estágio final da evolução da carga alostática se encerra na sobrecarga alostática, na qual a desregulação total dos sistemas fisiológicos levam ao adoecimento conhecido como "efeito terciário" 2,20 .

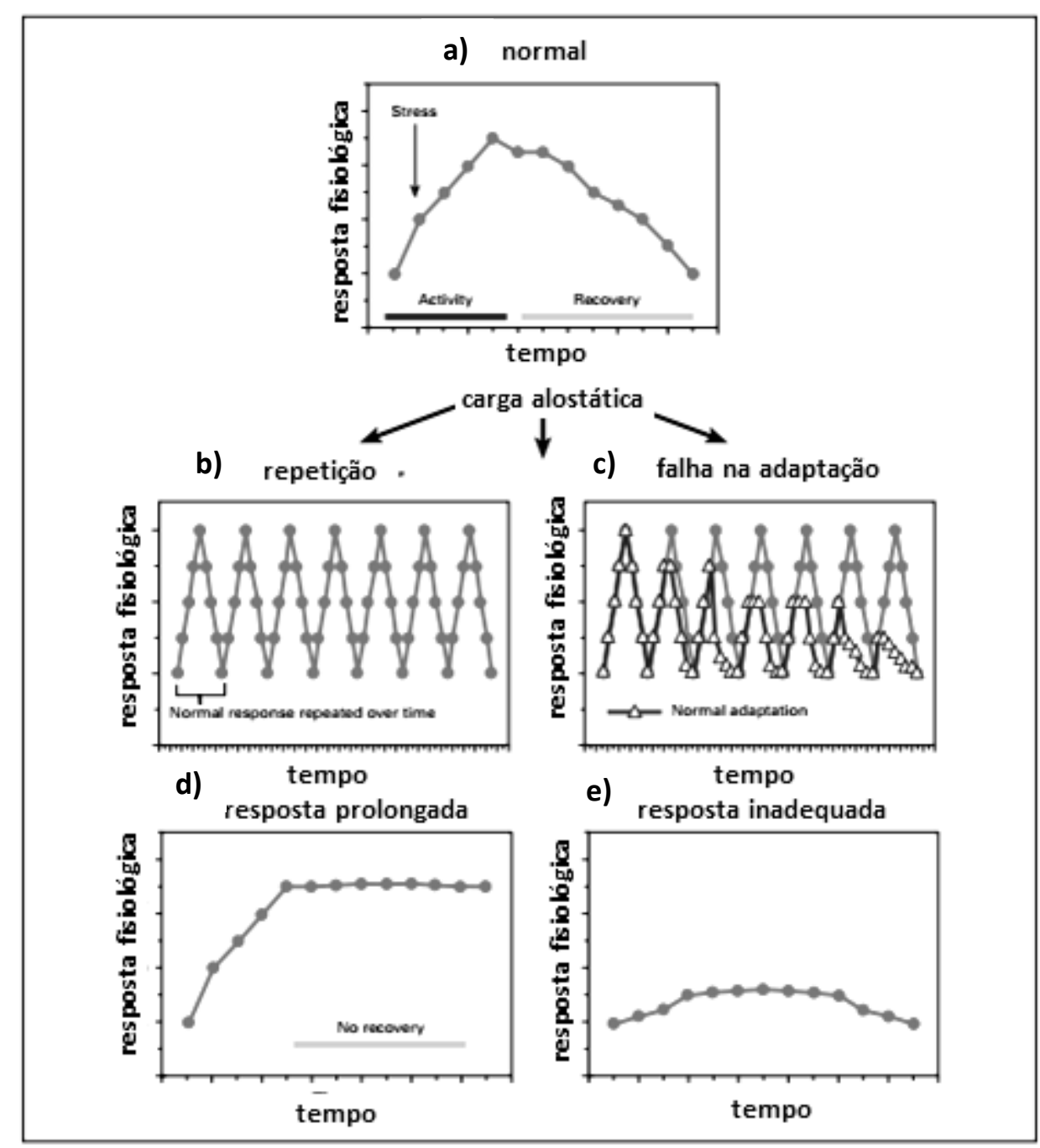


Figura 1. Reação alostática normal (A), exposição a eventos estressantes repetitivos (B), ausência de adaptação ao estresse crônico (C), ausência de recuperação ao funcionamento homeostático (D) e reações inadequadas decorrentes do estresse crônico (E). Fonte original: McEwen, 1998; adaptado por Mendonça (2014) ${ }^{3,21}$.

O modelo de carga alostática propõe que medindo estas interações multissistêmicas a partir dos mediadores primários e secundários do estresse, bem como de seus efeitos, avanços significativos podem ser alcançados na detecção de indivíduos com elevado risco para o desenvolvimento de doenças relacionadas ao estresse que ainda não apresentam sinais da doença (efeitos terciários), mas potencialmente manifestam padrões bioquímicos subclínicos 19,20 .

Vários autores demonstraram que a exposição prolongada ou recorrente ao intenso papel catabólico dos glicocorticóides e catecolaminas (mediadores primários do sistema alostático) altera as concentrações de insulina, e a pressão sanguínea, aumentando assim, o risco para o desenvolvimento de diabetes, hipertensão arterial e doenças ateroscleróticas ${ }^{6,19}$. Além disso, o sistema HPA suprime as funções imunológicas, o que em situações crônicas está associado ao aumento do risco a infecções ${ }^{19,20}$.

Ademais, alterações no ritmo de secreção de cortisol (pico pela manhã e declínio gradual ao longo da tarde e noite) são sugestivas de carga ou sobrecarga alostática ${ }^{19}$. Indivíduos com depressão apresentam concentrações de cortisol maiores no período da tarde e à noite, comparados com indivíduos sem depressão ${ }^{22}$. Indivíduos com burnout e carga alostática elevada apresentam hiporresposta de cortisol ao acordar e mediante exposição a estresse psicossocial agudo ${ }^{19}$.

Neste sentido faz-se necessário investigar se os profissionais de enfermagem apresentam carga alostática e alterações no ritmo de secreção de cortisol, a fim de identificar os indivíduos com maior risco ao adoecimento por doenças relacionadas ao estresse. Ao longo do processo de cuidar, o estresse pode se tornar prejudicial não apenas para o profissional, mas também para o paciente, uma vez que os prejuízos físicos e emocionais decorrentes da sobrecarga na equipe podem influenciar a qualidade da assistência prestada, bem como a eficácia do cuidado ${ }^{4}$. 


\subsection{Enfermagem e estresse: porque a enfermagem é uma profissão estressante?}

Mediante o conceito de que situações novas, imprevisíveis, incontroláveis e socialmente avaliativas são capazes de mobilizar a reação de estresse (Mason 1968; Dickerson e Kemeny, 2004), é razoável assumir que os profissionais de enfermagem estão expostos diariamente a situações estressantes e, consequentemente aos seus efeitos negativos e cumulativos. Seja na novidade presente num caso clínico atípico ou em um conflito interpessoal, na imprevisibilidade e falta de controle sobre o absenteísmo de trabalhadores da equipe associado à superlotação das unidades de atendimento ou na avaliação social negativa do outro a respeito do trabalho da equipe de enfermagem ${ }^{21}$.

Além disso, segundo o Instituto Nacional de Segurança e Saúde Ocupacional (National Institute for Occupational Safety and Health - NIOSH) o estresse relacionado ao trabalho é definido como respostas físicas e emocionais prejudiciais que ocorrem quando as demandas do trabalho não correspondem às capacidades, recursos ou necessidades do trabalhador ${ }^{23}$.

Confirmando esta premissa, um estudo conduzido pela Associação Americana de Enfermagem (American Nursing Association - ANA) revelou que o estresse e o excesso de trabalho estão entre as principais causas de preocupação em relação à segurança e saúde nos profissionais de enfermagem ${ }^{24}$. Mais de $55 \%$ dos profissionais de enfermagem consideram o estresse um elemento importante e presente na vida profissional ${ }^{25}$ e muitos estudos identificaram níveis elevados de estresse nestes trabalhadores ${ }^{26,27,28}$.

Fatores, de caráter físico e emocional, associados ao cuidado do paciente, ao regime e ambiente de trabalho têm sido associados ao estresse nos profissionais de enfermagem. Especificamente, a necessidade de lidar com a dor, sofrimento e morte dos pacientes, impotência frente a prognósticos ruins, carga de cuidado e relacionamento interpessoal paciente-profissional configuram entre os principais elementos associados com estresse elevado ${ }^{29}$. Em relação ao regime de trabalho, a diversidade de atividades executadas, as interrupções frequentes e os imprevistos são fatores agravantes no trabalho de enfermagem que, consequentemente, podem conduzir ao desgaste mental ${ }^{30}$.

Além disso, o ambiente desgastante, baixa remuneração, duplo vínculo empregatício, longas jornadas de trabalho, sobrecarga de atividades, conflitos interpessoal, indefinição de papel, baixo grau de suporte social de supervisores e colegas de trabalho, recompensas, 
discriminação, perseguição, quantidade insuficiente de profissionais para o cuidado, bem como limitação na tomada de decisões também podem exceder às capacidades e recursos de enfrentamento destes profissionais ${ }^{31}$.

Tensão, violência e acidentes de trabalho também foram considerados elementos desencadeadores de estresse em profissionais de enfermagem ${ }^{32}$. Além disso, um alto nível de estresse ocupacional e burnout apresentam efeito negativo sobre o cuidado ao paciente e pode comprometer a qualidade da assistência ${ }^{33}$.

No tocante ao ambiente de trabalho, a permanência em setor fechado com iluminação artificial, ar condicionado e ruídos constantes têm sido apontados como fontes de estresse para o profissional de enfermagem ${ }^{34}$.

Ademais, o estresse no trabalho está associado à insatisfação profissional, queixas físicas e absenteísmo ${ }^{35,36,37}$. Em relação a isso, um estudo revelou que a taxa mensal de absenteísmo na equipe de enfermagem está acima do proposto pelo COFEN resolução n²93/2004, representando aproximadamente 10.452 dias perdidos de trabalho ${ }^{38}$.

Taxas elevadas de depressão, transtornos de ansiedade, síndrome do pânico, distúrbios do sono, sentimentos de inadequação, baixa autoestima, irritabilidade, doenças gastrointestinais e osteomusculares, além de número significativo de consultas psiquiátricas e casos de suicídio representam o impacto negativo do estresse crônico na saúde dos profissionais de enfermagem ${ }^{39,40,41,42}$.

A quantidade de estudos que demonstram o quanto o profissional de enfermagem se percebe estressado e o quanto isso afeta seu bem-estar psicoemocional e sua saúde nos faz refletir a respeito de como os mediadores biológicos da reação de estresse se expressam nestes trabalhadores.

\subsection{Impacto biológico do estresse crônico nos profissionais de enfermagem}

Ao analisar o estresse e a secreção de cortisol em profissionais de enfermagem que trabalhavam em turno diurno, vários estudos demonstraram que os trabalhadores apresentavam maior concentração de cortisol em dias de trabalho em comparação aos dias de folga ${ }^{43,44,45}$, principalmente em relação à concentração de cortisol 30 minutos após acordar . 
Curiosamente os estudos que analisaram a concentração de cortisol nos profissionais de enfermagem não identificaram associação significativa entre o cortisol e percepção subjetiva de estresse, carga horária semanal ${ }^{46}$ e sobrecarga de trabalho ${ }^{47}$.

Além disso, o único estudo encontrado sobre mediadores alostáticos da resposta de estresse evidenciou que profissionais da saúde com síndrome de burnout apresentam maior carga alostática associada à baixa concentração de cortisol pela manhã (hiporresposta ao acordar) em relação aos profissionais sem burnout ${ }^{48}$.

Os poucos estudos disponíveis na literatura evidenciam uma lacuna de conhecimento em relação aos mediadores biológicos de carga alostática, bem como alterações no ritmo de secreção de cortisol nos profissionais de enfermagem evidenciando a necessidade de investigação nesta temática uma vez que os estudos mostram extensivamente a exposição crônica e intensa dos profissionais de enfermagem ao estresse. 
OBJETIVOS 


\section{OBJETIVOS}

\subsection{Gerais:}

- Descrever a frequência de profissionais de enfermagem com carga alostática elevada e ritmo atípico de secreção de cortisol em profissionais de enfermagem de unidades hospitalares.

- Analisar se a carga alostática elevada está associada com o ritmo atípico de secreção de cortisol.

\subsection{Específicos:}

- Analisar se características sociodemográficas e os antecedentes de saúde interferem na carga alostática e no ritmo de secreção de cortisol.

- Analisar se as características do regime de trabalho interferem na carga alostática e no ritmo de secreção de cortisol. 
HIPÓTESE 


\section{HIPÓTESES}

- A frequência de profissionais de enfermagem sob carga alostática e com ritmo atípico de secreção diurna de cortisol é elevada;

- Profissionais de enfermagem com carga alostática elevada apresentam padrões atípicos de secreção diurna de cortisol, com concentrações alteradas pela manhã (hiper ou hipocortisolemia) e elevadas no período da noite;

- Profissionais de enfermagem alocados com mais tempo de trabalho e alocados em diferentes unidades de atendimento apresentam frequências diferentes de carga alostática elevada e de padrões atípicos de secreção diurna de cortisol. 
MÉTODO 


\section{MÉTODO}

\subsection{TIPO DE ESTUDO}

Trata-se de um estudo observacional prospectivo com abordagem quantitativa.

Este estudo faz parte de um projeto de pesquisa matriz intitulado "Avaliação de biomarcadores de estresse crônico em profissionais de enfermagem", em desenvolvimento sob financiamento da Fundação de Amparo à Pesquisa do Estado de São Paulo - FAPESP no protocolo 2013/01637-2.

Assim, o percurso metodológico, a seguir descrito, bem como os resultados apresentados, estão relacionados somente aos objetivos do presente estudo.

\subsection{CARACTERIZAÇÃO DO LOCAL DO ESTUDO}

O presente estudo foi desenvolvido na cidade de São Paulo, pela pós-graduação proposto pela Escola de Enfermagem da Universidade de São Paulo (EE-USP) e a coleta de dados ocorreu no Hospital Universitário da USP (HU-USP).

O HU-USP é um hospital de grande porte, de caráter público e referência no nível secundário de atenção à saúde da cidade de São Paulo. Por ser um hospital escola, sua missão está alicerçada no ensino, pesquisa e assistência. O HU-USP recebe alunos das diversas áreas de formação no ensino em saúde como acadêmicos de medicina, enfermagem, fonoaudiologia, nutrição, fisioterapia, terapia ocupacional, odontologia, farmácia e serviço social. O Hospital possui 178 leitos distribuídos entre as unidades de clinica médica, clínica cirúrgica, pediatria, obstetrícia, berçário, alojamento conjunto, unidade de terapia intensiva (adulto e pediátrico), além de leitos em pronto atendimento para observação adulto, infantil e obstétrica. $\mathrm{O}$ hospital conta também com atendimento ambulatorial. 


\subsection{PROCEDIMENTO ÉTICO}

O projeto de pesquisa foi aprovado pelos Comitês de Ética da EE-USP (parecer n. 403.390) e HU-USP (parecer n. 415.986) (Apêndice A).

Todos os participantes foram orientados sobre as implicações éticas e legais da pesquisa, suas etapas, não obrigatoriedade da participação e assinaram o Temo de Consentimento Livre Esclarecido (Anexo A).

\subsection{POPULAÇÃO DO ESTUDO}

\subsubsection{Amostra}

A amostra do estudo foi composta por 142 profissionais de enfermagem, dentre eles auxiliares, técnicos de enfermagem e enfermeiros, randomicamente selecionados, dos turnos da manhã e tarde, alocados nas unidades médico-hospitalar do Pronto Socorro adulto (PSA) e pediátrico (PSI), Clinica Médica (CM), Clinica Cirúrgica (CLC), Centro Cirúrgico (CC), Pediatria, Unidade de Terapia Intensiva adulto (UTI-A) e pediátrica (UTI-P), Hemodiálise, Centro Obstétrico e Ambulatório do HU-USP.

\subsubsection{Técnica de amostragem}

A seleção dos participantes se deu por técnica de amostragem aleatória, com sorteio dos funcionários por clínica, categoria profissional e turno de trabalho (manhã e tarde). O serviço de Educação Continuada do HU-USP forneceu na época uma lista com os nomes de todos os profissionais do turno diurno, totalizando 270 trabalhadores, distribuídos nas categorias "enfermeiro", "técnico e auxiliar de enfermagem" de cada unidade do HU-USP. A quantidade de profissionais sorteados por clínica, categoria profissional e turno de trabalho seguiu o percentual real de funcionários do turno diurno. Essa estratégia foi utilizada para que a amostra representasse com maior fidedignidade a população de profissionais de enfermagem do HU-USP. Foram considerados 222 funcionários registrados na lista para o sorteio dos participantes. Sessenta e dois profissionais foram excluídos por uso de medicações psicoativas ou esteroide, falta de disponibilidade para participar de todas as etapas do protocolo de estudo (coleta de sangue) ou falta de interesse. Cento e sessenta iniciaram o protocolo de estudo, 
porém 18 desistiram durante a coleta de dados por indisponibilidade para coleta de sangue ou saliva. Foram consideradas estratégias de facilitação para estas etapas aos desistentes (exemplo: coleta do sangue em domicílio, recoleta da saliva). Entretanto, isto não modificou a decisão de retirar o consentimento e interromper a coleta de dados.

\subsubsection{Critérios de inclusão}

Os indivíduos que preencheram todos os critérios de inclusão listados foram elegíveis para o estudo:

- Pertencer ao quadro de colaboradores de enfermagem da instituição por no mínimo um ano;

- Ter disponibilidade para participar de todas as etapas do projeto;

- Pertencer ao turno diurno.

\subsubsection{Critérios de exclusão}

Indivíduos que se enquadraram em uma ou mais alternativas a seguir foram excluídos do estudo:

- Licença médica superior a 15 dias nos últimos 30 dias;

- Ter retornado das férias nos últimos 30 dias;

- Tabagista ou história prévia nos últimos cinco anos;

- Uso abusivo de bebida alcoólica e outras drogas ou história prévia nos últimos cinco anos;

- Uso de medicações que influenciam o funcionamento do eixo hipotálamo-pituitáriaadrenal (glicocorticoides, esteroides, beta bloqueador, antidepressivos ou qualquer medicação psicoativa);

- Ter feito uso de glicocorticoides nos últimos três meses;

- Diagnóstico médico de doença neurológica ou psiquiátrica; 
- Atividade laboral em outra instituição no turno noturno.

Cabe destacar que os profissionais de enfermagem do HU-USP, assim como a própria instituição, possuem um perfil diferenciado em comparação com profissionais de outras instituições hospitalares. São profissionais com alta qualificação profissional, ou seja, a maioria dos auxiliares/técnicos de enfermagem possui ou está em vias de concluir graduação em enfermagem; a maioria dos enfermeiros possui pós-graduação lato sensu e stricto sensu e possuem média salarial acima da faixa estimada para a categoria. Além disso, estes profissionais possuem maior autonomia de atuação e participam, com frequência, de cursos de aperfeiçoamento, capacitação e atualização, permitindo aproximação constante entre a prática clínica e a implementação de evidências de cuidado disponíveis na literatura. Estes profissionais desempenhavam suas atividades de trabalho sob regime de 36 horas semanais, sendo 6 horas diárias durante a semana com um plantão de 12 horas no final de semana (sábado ou domingo).

\subsection{VARIÁVEIS DE INTERESSE E MÉTODO DE ANÁLISE}

a) Dados sociodemográficos, relacionados ao trabalho e à saúde: questionário contendo informações sociodemográficas (idade, sexo, escolaridade, avaliação econômica, renda mensal), relacionadas ao trabalho (categoria profissional, tempo de profissão, tempo de trabalho no HU-USP, jornada dupla diurna em outra instituição, últimas férias) e relacionadas a antecedentes de saúde (doenças crônicas, medicações em uso, período menstrual), (Anexo B).

b) Ritmo diurno de secreção de cortisol: Foi analisado a partir de amostras salivares coletadas em ambiente domiciliar pelo próprio participante mediante orientações prévias. Estas amostras foram obtidas a partir de salivettes contendo algodão (Figura 3), o qual o indivíduo mastigava por aproximadamente 03 minutos, sendo este, retirado da boca e colocado em um tubo seco de $05 \mathrm{ml}$. Posteriormente à coleta, o participante armazenava o material no refrigerador de sua casa até o término da coleta quando o participante deveria devolver as amostras ao pesquisador. As amostras de saliva foram coletadas durante dois dias úteis, consecutivos, imediatamente ao acordar, 30 minutos após acordar, às 14 horas, às 16 horas e antes de dormir. As concentrações de cortisol obtidas na primeira hora após acordar evidenciam o pico circadiano desde glicocorticoide, sendo considerado um indicador 
confiável da atividade basal do eixo HPA ${ }^{6}$. Já as concentrações de cortisol adicionais a serem obtidas à tarde e a noite tem sido considerada marcadores confiáveis do ritmo diurno de secreção do cortisol ${ }^{7}$. A determinação da coleta do material em dois dias úteis ocorreu em função do fato de que uma única amostra poderia evidenciar um padrão atípico devido a algum evento isolado ocorrido no dia da coleta.

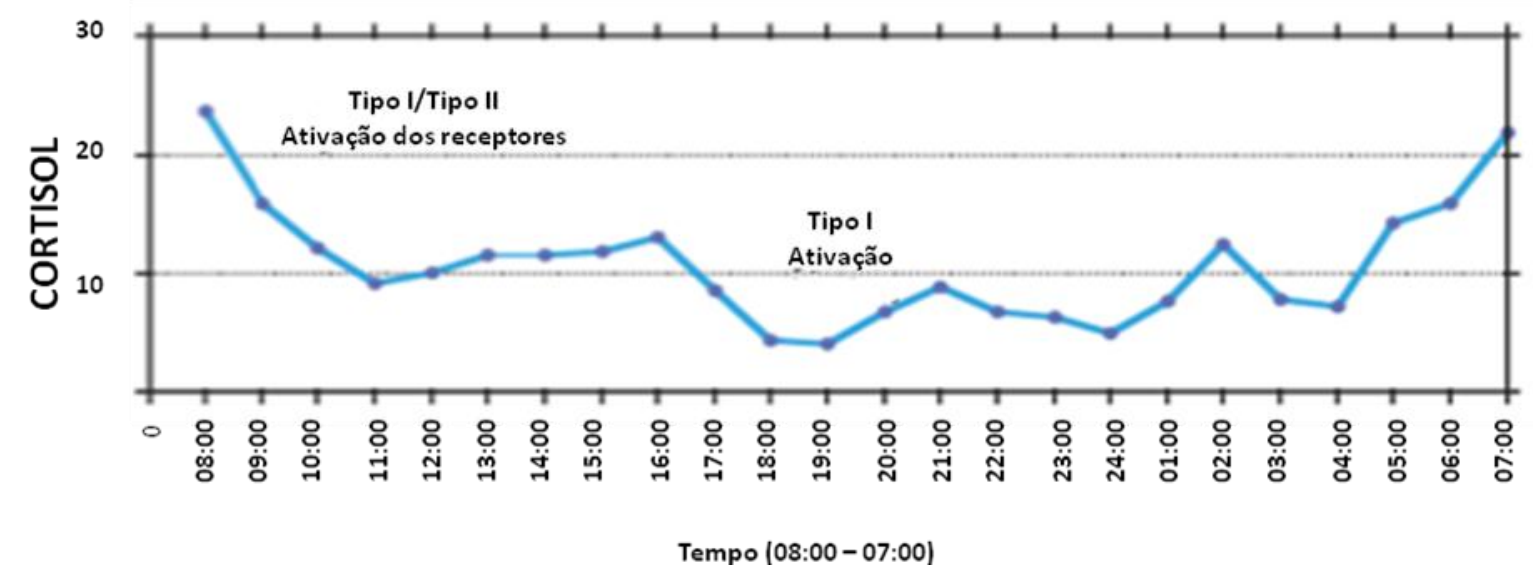

Figura 2. Ritmo circadiano de secreção de cortisol em humanos. Fonte: Lupien et al, 2007; adaptado por Mendonça, $2014^{21,47}$.

Para monitorizar o horário de coleta, e analisar sua confiabilidade em relação aos horários predeterminados, foi dispositivo eletrônico de monitorização ("Medical Event Monitoring System - MEMS®”), desenvolvido para compilar o histórico de coleta dos participantes a partir de um circuito microeletrônico, implantando na tampa dos frascos onde são mantidos os salivettes, que registra o número de vezes em que o frasco foi aberto e fechado (Figura 4). Os eventos (abertura e fechamento do frasco) foram registrados e armazenados no MEMS ${ }^{\circledR}$ implantados nos frascos, sendo transferidos para um computador via cabo USB conectado a um leitor específico do MEMS®. Os registros são decodificados por um software que analisa e apresenta as informações relacionadas data e horários de aberto e fechamento dos frascos, permitindo, então, verificar se a coleta foi realizada em dia útil, de trabalho e não folga, bem como se o horário de abertura do frasco foi o mesmo orientado verbalmente e por escrito ao participante. Este método de análise da confiabilidade das amostras tem sido considerado "padrão ouro" para analisar amostras de saliva coletadas pelos participantes ${ }^{49}$. Além disso, com o objetivo de evitar que o participante se esquecesse dos horários de coleta estipulados foram enviadas mensagens de texto via telefone móvel (SMS) no dia anterior ao início da coleta, alertando sobre a necessidade da coleta no dia seguinte ao acordar; 15 minutos antes de cada coleta da tarde (14h e 16h) e à noite antes do horário 
habitual de dormir. Estes envios ocorreram nos dois dias de coleta de saliva. Além das mensagens tipo SMS, o participante recebia um diário de coleta, no qual ele deveria anotar todos os horários em que foram coletadas as salivas, bem como seu horário habitual de acordar e dormir. Caso algum imprevisto (exemplo: esquecimento, acontecimentos na vida pessoal que o impedisse da coleta) o mesmo era orientado a entrar em contato com o pesquisador para comunicar o ocorrido e era orientado a iniciar uma nova coleta. Neste caso, o participante recebia um novo kit para coleta das amostras de saliva, novo diário de registro, além do reforço das orientações para coleta adequada.

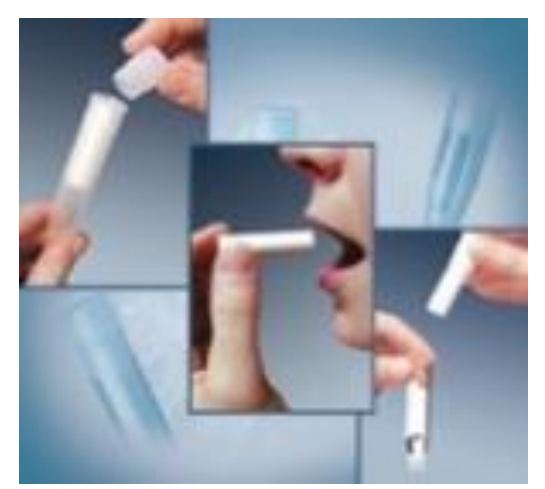

Figura 3. Procedimento de coleta de saliva no salivette. Fonte: https://www.sarstedt.com/filead min/user_upload/99 Broschuer en/Englisch/156_Salivette_GB 0813.pdf

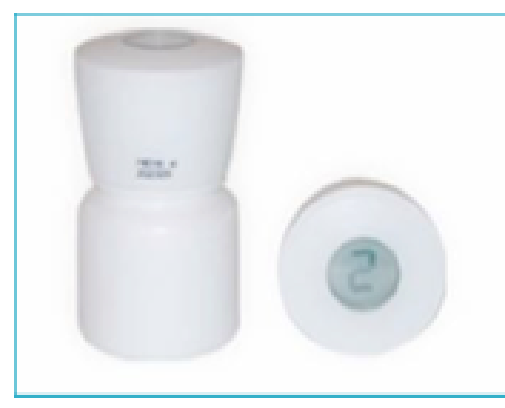

Figura 4. Medical event monitoring system, (mens) Fonte: http://www.mwvaardex.com/Pr oducts/DataCollection/MEMS Cap/

c) Indicadores biológicos de carga alostática (estresse crônico). Em situações de estresse existe a liberação de alguns mediadores primários e secundários de reação do estresse (sistema alostático), responsável por manter o funcionamento do organismo em equilíbrio, que sinalizam se este sistema protetor está em situação de carga ou sobrecarga (carga alostática) ${ }^{16,19}$. Bastante descrito na literatura científica e validado no estudo internacional "MacArthur Studies for Sucessful Aging" ${ }^{20}$ com potencial para implicações clínicas, esse mediadores sinalizam indiretamente o funcionamento dos sistemas cardiovascular, imunológico, metabólico e neuroendócrino, principais alvos dos efeitos mediadores da resposta de estresse. A análise conjunta desses mediadores reflete a interação multissistêmica da reação biológica do estresse, e é feita a partir de um índice (Índice de Carga Alostática ICA ${ }^{19}$ que analisa a carga alostática e classifica os indivíduos com maior risco para desenvolver doenças relacionadas ao estresse (carga alostática elevada). O ICA é composto pela análise de mediadores neuroendócrinos (cortisol plasmático e dehidroepiandrosterona 
sulfatada - DHEA-S), metabólicos (colesterol total, colesterol HDL, hemoglobina glicada), cardiovasculares (pressão arterial sistólica e diastólica obtidas em três medidas em situação de repouso), antropotrométricos de risco cardiovascular (razão cintura/quadril) e mediadores imunológicos (fibrinogênio e proteína $\mathrm{C}$ reativa) de carga alostática. Com base nos valores laboratoriais de referência desses biomarcadores, calcula-se o percentil 75 e 25 destes valores. Os resultados com valores acima ou abaixo destes percentis são considerados sinais subclínicos de estresse crônico e sinalizam o desgaste do sistema alostático. Os indivíduos que apresentaram valores dos mediadores descritos acima do percentil 75 (ou abaixo do percentil 25 para DHEA-S e colesterol HDL) ganha um ponto no ICA. Considerando a análise de 10 marcadores, a pontuação para o ICA varia entre 0 a 10 pontos, sendo que um zero ponto significa nenhum marcador com alteração subclínica e 10 pontos, todos os marcadores alterados. Quanto maior a pontuação no ICA, maior a carga alostática. O risco para desenvolvimento de doenças relacionadas ao estresse aumenta quanto maior for a pontuação obtida no índice. Para análise desses biomarcadores, foram coletadas, em um único dia, amostras de sangue de todos os participantes, bem como, verificada sua pressão arterial e medidas antropométricas. As análises das amostras foi realizada pela Divisão de Laboratório Clínico do Hospital Universitário da USP. A metodologia, equipamentos e reagentes utilizados foram:

Cortisol plasmático: Metodologia utilizada - Imunoensaio competitivo utilizando quimioluninescência Equipamento : Advia Centaur Siemens ${ }^{\circledR}$ - Reagente - Siemens

DHEA-S: Metodologia utilizada - Imunoensaio competitivo utilizando quimioluninescência Equipamento : Advia Centaur Siemens ${ }^{\circledR}$ - Reagente - Siemens

Colesterol total: Metodologia utilizada- Método enzimático colorimétrico (colesterol oxidase) Equipamento: ADVIA 1800 Siemens ${ }^{\circledR}$ - Reagente - Siemens

Colesterol HDL: Metodologia utilizada- Método enzimático colorimétrico homogêneo sem precipitação Equipamento: ADVIA 1800 Siemens ${ }^{\circledR}$ - Reagente - Siemens

Hemoglobina glicada: Metodologia utilizada - Cromatografia Líquida de Alta Resolução (HPLC) por troca iônica Equipamento: D-10 da BIORAD®

Fibrinogênio: Metodologia utilizada - sistema ótico-mecânico baseado no aumento de viscosidade do plasma a ser testado - Equipamento: STA Compact Stago® Reagente - STAFib 2® (Diagnóstica STAGO)

Proteína C reativa: Metodologia utilizada- Método imunoquímico (Nefelometria) Equipamento: Nefelômetro BNII Siemens ${ }^{\circledR}$ - Reagente - Siemens 


\subsection{PROCEDIMENTOS DE COLETA DE DADOS}

Inicialmente o projeto de pesquisa foi apresentado às chefias de enfermagem das unidades de atendimento do HU-USP, bem como aos representantes das categorias de técnico e auxiliar de enfermagem de cada unidade em uma reunião de conselho administrativo do Departamento de Enfermagem do hospital. O objetivo desta apresentação foi de que as chefias e representantes dos profissionais de enfermagem pudessem divulgar o estudo e comunicar que pesquisadores da EE-USP estariam nas unidades desenvolvendo a pesquisa.

Posteriormente, cada profissional de enfermagem sorteado para o estudo foi abordado em sua própria unidade de trabalho em local reservado e privativo. Aos que preenchessem os critérios de inclusão e exclusão foram esclarecidas todas as etapas do estudo e solicitado a assinatura do Termo de Consentimento Livre e Esclarecido (TCLE). Imediatamente após, os participantes iniciavam o protocolo de estudo que ocorreu em quatro etapas:

1a. Etapa - Entrevista individual: Coleta de informações sociodemográficas (idade, sexo, escolaridade, avaliação econômica, renda mensal), relacionadas ao trabalho (categoria profissional, tempo de profissão, tempo de trabalho no HU-USP, tempo de percurso da residência até o trabalho, jornada dupla diurna em outra instituição, últimas férias) e relacionadas a antecedentes de saúde (doenças crônicas, medicações em uso, período menstrual). Nesta mesma entrevista, que durava aproximadamente 40 minutos, os participantes tinham suas medidas antropométricas avaliadas (peso (verificado na balança digital TECHLINE®), altura, circunferência abdominal e do quadril), sua pressão arterial aferida (três momentos diferentes 0, 30, 50 minutos após o início da entrevista, com aparelho de aferição digital OMRON®) e eram orientados sobre a coleta de saliva (2 $2^{a}$ Etapa) e demais das etapas do estudo. Após as orientações, o participante recebia um kit para coleta de saliva durante dois dias consecutivos de trabalho. Este kit era composto por uma caixa de isopor (3 litros), dois recipientes (garrafas plásticas pequenas) identificados como "Dia 1" e "Dia 2" e que continham em sua tampa os dispositivos de monitorização do horário de coleta (MEMS $\left.{ }^{\circledR}\right)$, um gelo reciclável para retorno das amostras de saliva, além de um diário de coleta de saliva (Anexo C). Este diário, continha orientações escritas sobre o procedimento, dias e horários para coleta da saliva. Além da orientação escrita, o participante era informado verbalmente sobre o procedimento para coleta de saliva durante dois dias consecutivos de 
trabalho, bem como sobre a necessidade de rigor no cumprimento dos horários estabelecidos, registro dos mesmos no diário de coleta de saliva e não coleta em dias de folga, final de semana ou falta no trabalho. O pesquisador disponibilizava seu contato telefônico para necessidade de eventual esclarecimento durante a coleta de saliva e anotava o número do telefone móvel do participante informando que o mesmo receberia antes de cada coleta de saliva uma mensagem de texto do tipo SMS lembrando sobre a coleta, o jejum e o horário pré-agendado. O participante foi orientado a coletar as amostras de saliva na mesma semana da entrevista inicial e armazená-las na geladeira até a data de devolução no HU-USP.

2a Etapa - Coleta de saliva: No dia seguinte à entrevista, exceto nos finais de semana e dia de folga, o participante coletava amostras de saliva ao longo de dois consecutivos nos horários ao acordar, 30 minutos após acordar, às 14h, às $16 \mathrm{~h}$ e ao dormir. Todos os participantes foram orientados, verbalmente e por escrito sobre como coletar o material e a tomarem os seguintes cuidados durante a coleta:

$1^{\text {a }}$ amostra ao acordar: o participante deveria estar em jejum, sem ingerir alimentos ou escovar os dentes antes da coleta.

$2^{\mathrm{a}}$ amostra 30 minutos após acordar: permanecer em jejum e sem escovar os dentes.

$3^{\mathrm{a}}$ e $4^{\mathrm{a}}$ amostra à tarde: não ter ingerido alimentos ou bebidas de qualquer tipo nos últimos 30 minutos antes da coleta. As mulheres foram orientadas a retirar batom caso estivessem usando.

5 amostra ao dormir: não ter ingerido alimentos ou bebidas de qualquer tipo nos últimos 30 minutos; respeitar o horário habitual de dormir. As mulheres foram orientadas a retirar batom caso estivessem usando.

Os participantes foram alertados sobre a necessidade de respeitar os horários de coleta com fidedignidade evitando que suas amostras pudessem ser invalidadas na detecção de que os horários não tinham sido adequadamente seguidos. Igualmente, os profissionais foram orientados a relatarem qualquer inadequação durante a coleta para que a mesma fosse corrigida e não houvesse, portanto, prejuízo em seu resultado.

3 Etapa - Coleta de sangue: Na mesma semana em que ocorreu a entrevista, o participante foi submetido à coleta de sangue em jejum de 10 a 12 horas em sua própria unidade de 
trabalho, em local privativo e reservado. Após a coleta, o participante recebia um kit desjejum composto por alimentos não perecíveis (suco em embalagem tetra-pak, cereal em barra, biscoito salgado). Cabe esclarecer, que na véspera da coleta de sangue, o participante recebia uma mensagem SMS em seu telefone móvel no final do dia lembrando sobre a necessidade de jejum para a coleta no dia seguinte. A coleta de sangue foi feita por profissional técnico de enfermagem, com registro e certificação profissional ativo, treinado para execução do protocolo de pesquisa. Este profissional foi treinado e orientado quanto ao protocolo de pesquisa, coleta do material biológico, armazenamento e fluxo de entrega deste material para análise no laboratório do HU-USP.

4a Etapa - Desfecho: Cinco dias após a coleta de sangue, o participante recebeu o pesquisador novamente em sua unidade de trabalho para entregar as amostras de saliva coletadas, receber os resultados dos exames de sangue, bem como sua interpretação e encaminhamento no caso de exame alterado, além de receber $\mathrm{R} \$ 60,00$ em dinheiro como ajuda de custo para cobrir despesas com alimentação e transporte nos dias de coleta de dados. Todos os participantes com resultados alterados nos biomarcadores de carga alostática foram encaminhados para avaliação agendada no ambulatório do HU-USP e a procurarem o médico de referência ou de acompanhamento de saúde quando fosse o caso. 


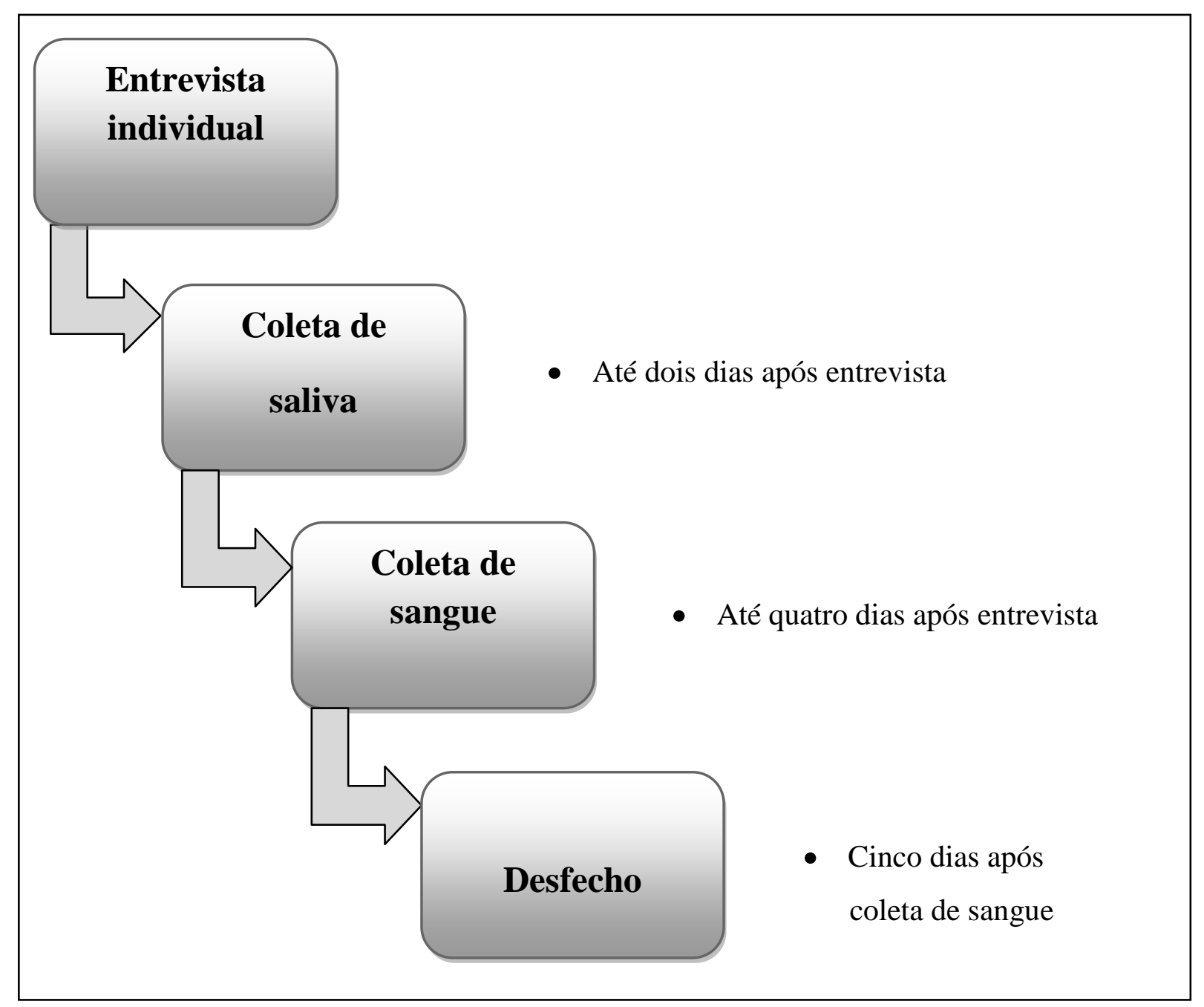

Figura 5. Representação esquemática do procedimento de coleta de dados.

\subsection{TRATAMENTO ESTATÍSTICO}

Inicialmente as variáveis foram analisadas do ponto de vista descritivo com médias, desvio-padrão e distribuição de frequência. Para análise dos testes de hipóteses, as variáveis foram inicialmente analisadas quanto à distribuição normal. As concentrações de cortisol não apresentaram distribuição normal, sendo, portanto transformadas na base logarítmica antes de serem submetidas ao tratamento estatístico apropriado.

Para análise do ritmo diurno de secreção de cortisol, utilizou-se ANOVA para medidas repetidas com correção de Greenhouse na ausência de esfericidade no padrão de distribuição das variáveis. As comparações múltiplas (post hoc) foram feitas com teste de Bonferroni. A 
variável idade, escolaridade, uso de anticonceptivo oral e fase do ciclo menstrual em que a amostra de saliva foi coletada foram inseridas no modelo estatístico e na ausência de efeito ou interação significativa foram excluídas $(\mathrm{p}>0,20)$.

Para analisar a quantidade de cortisol secretada ao longo do dia foi calculada a área sob a curva (AUC). Este método de análise de cortisol já foi descrito e validado e se baseia na fragmentação da $\mathrm{AUC}$ em vários trapézios ${ }^{50}$. Esta área corresponde às concentrações de cortisol obtidas nos diferentes tempos ao longo do dia. Calcula-se, assim a área de cada trapézio e a somatória destas áreas representa uma medida global de secreção de cortisol. Denominou-se AUC total à concentração de cortisol secretada ao longo de todo o dia, e AUC reatividade ao despertar (AUC CAR) à concentração de cortisol secretada no período da manhã em resposta às demandas fisiológicas impostas pelo ato de despertar.

Para classificação do ritmo de secreção de cortisol, primeiramente foi calculada a inclinação da curva de concentração de cortisol através da função "slope" do software Excel® para cada dia de coleta de saliva. Posteriormente, obteve-se a diferença entre o "slope" do primeiro dia e do segundo dia de coleta e o respectivo desvio-padrão. O participante que tivesse o valor absoluto da diferença de "slope" superior ao desvio-padrão foi classificado como inconsistente, e valores inferiores foram denominados "típicos". Para a classificação do padrão "flat", obteve-se a média do "slope" dos dois dias. Os participantes com médias mais positivas foram classificados como "flat" 7 .

Para análise de frequências (padrão de cortisol x categoria profissional ou x setor de trabalho) foi utilizado o teste Qui-quadrado ou teste exato de Fischer.

As comparações entre duas médias foram realizadas com o teste T-Student e entre três médias com teste ANOVA uma via.

O percentil 75 e 25 do ICA para cada biomarcador foi calculado seguindo exemplo a seguir: Colesterol total com valor de referência igual a 3,3 a 5,2 $\mathrm{mmol} / \mathrm{l}$. Primeiramente, subtrai-se o limite inferior do valor de referencia de seu respectivo limite superior $(5,2-3,3=$ 1,9). A seguir, determina-se o quartil, dividindo a diferença obtida $(1,9)$ por quatro $(1,9 / 4=$ 0,475). Para obter o ponto de corte que classifica o indivíduo em carga alostática elevada, subtrai-se o quartil 0,475 do limite superior do valor de referência $(5,2-0,475=4,725)$ ou soma-se o quartil 0,475 ao limite inferior do valor de referência para os biomarcadores colesterol HDL e DHEA-S, para os quais valores baixos representam risco. Assim, um 
participante com colesterol total igual a $4,725 \mathrm{mmol} / 1$ ou maior ganha um ponto no ICA. Valores abaixo deste valor pontuam zero. O ICA foi obtido pela soma dos biomarcadores subclinicamente desregulados, ou seja, com valores acima do percentil 75 ou abaixo do percentil 25 para colesterol HDL e DHEA-S ${ }^{19}$.

Para classificar o indivíduo com carga alostática elevada, calculou-se a mediana do ICA. Os profissionais com valores acima da mediana do ICA foram classificados como “carga alostática elevada".

Para análise de associação entre variáveis contínuas (ICA, cortisol, tempo de trabalho) foi utilizado modelo de regressão linear ou multivariada, bem como coeficientes de correlação de Pearson.

Os dados foram armazenados e analisados utilizando o programa estatístico SPSS versão 14.0, e o nível de significância adotado foi de 5\%. 
RESULTADOS 


\section{RESULTADOS}

\subsection{CARACTERIZAÇÃO SOCIODEMOGRÁFICA E ANTECEDENTES DE SAÚDE:}

A amostra foi composta predominantemente por profissionais de enfermagem do sexo feminino $(n=128,90,1 \%)$, sendo em sua maioria casados $(n=94,66,1 \%)$, com idade média igual a 39,54 (DP \pm 9,6) anos e escolaridade média de 15,93 (DP \pm 2,97) anos de estudo. Em relação à classificação econômica, 40,1\% $(\mathrm{n}=61)$ pertencia à classe social B2, seguido por $33,2 \%(n=51)$ da classe social B1 e os demais distribuídos entre as classes A e C. (Tabela 1 e 2).

Tabela 1. Caracterização da amostra de profissionais de enfermagem do Hospital Universitário da USP segundo idade e escolaridade. São Paulo, 2015.

\begin{tabular}{llllll}
\hline Variável & $\mathbf{N}$ & Mínimo & Máximo & Média & DP \pm \\
\hline Idade & 142 & 23 & 67 & 39,54 & 9,59 \\
Escolaridade & 142 & 11 & 27 & 15,93 & 2,97 \\
\hline
\end{tabular}

Tabela 2. Caracterização sociodemográfica da amostra de profissionais de enfermagem do Hospital Universitário da USP segundo sexo, estado civil e nível socioeconômico. São Paulo, 2015.

\begin{tabular}{lcc}
\hline Variável & N & \% \\
\hline Sexo & 128 & 90,1 \\
Feminino & 14 & 9,9 \\
Masculino & & \\
Estado civil & 36 & 25,4 \\
Solteiro & 94 & 66,1 \\
Casado & 12 & 8,5 \\
Divorciado & & 7 \\
Classificação social & 1 & 11,4 \\
A1 & 17 & 33,2 \\
A2 & 51 & 40,1 \\
B1 & 61 & 8,3 \\
B2 & 12 & 0 \\
C & 0 & 100 \\
D & 142 & \\
\hline Total & & \\
\hline
\end{tabular}


Quanto aos antecedentes pessoais de saúde, a maioria não possuía doença crônica. Dos que possuíam, a hipertensão arterial foi a afecção mais frequentemente referida. (Tabela 3).

Tabela 3. Distribuição da amostra de profissionais de enfermagem do Hospital Universitário da USP segundo antecedentes pessoais e uso de medicações. São Paulo, 2015

\begin{tabular}{lcc}
\hline Variável & Não & Sim \\
& n $(\boldsymbol{\%})$ & n $(\boldsymbol{\%})$ \\
\hline Diabetes & $122(85,9)$ & $20(14,1)$ \\
Hipertensão Arterial & $117(82,4)$ & $25(17,6)$ \\
Acidente Vascular Cerebral & $136(95,8)$ & $6(4,2)$ \\
Insuficiência Coronariana & $139(97,9)$ & $3(2,1)$ \\
Medicações em uso & $104(73,2)$ & $38(26,8)$ \\
\hline
\end{tabular}

\subsection{CARACTERIZAÇÃO DA AMOSTRA QUANTO AO REGIME DE TRABALHO E CATEGORIA PROFISSIONAL}

Todos os colaboradores trabalhavam em regime de 36 horas semanais $\mathrm{e}$ desempenhavam a profissão há pelo menos dois anos. (Tabela 4).

Tabela 4. Classificação da amostra de profissionais de enfermagem segundo carga horária semanal de trabalho, tempo de trabalho na profissão e tempo de trabalho no Hospital Universitário da USP. São Paulo, 2015.

\begin{tabular}{lccccc}
\hline Variável & N & Mínimo & Máximo & Média & DP \pm \\
\hline Carga horária semanal & 142 & 36 & 40 & 36,03 & 0,33 \\
Quantidade horas trabalho & 142 & 1 & 44 & 3,16 & 6,21 \\
Tempo de trabalho na profissão & 142 & 2 & 44 & 15,30 & 8,93 \\
Tempo de trabalho no HU & 142 & 0 & 36 & 11,84 & 8,90 \\
\hline
\end{tabular}

Quanto ao turno de trabalho, 46,1\% $(n=65)$ estavam alocadas no turno da manhã e $53,9 \%(\mathrm{n}=76)$ no turno da tarde.

A maioria dos profissionais que compuseram a amostra eram técnicos de enfermagem, e estavam alocados predominantemente na unidade da UTI adulto e pediátrica. Considerando as características das unidades de atendimento, a maioria dos profissionais trabalhavam nas unidades críticas e eram técnicos de enfermagem. (Tabela 5 e 6). 
Tabela 5. Classificação da amostra de profissionais de enfermagem segundo a categoria profissional e alocação nas unidades de atendimento do Hospital Universitário da USP. São Paulo, 2015.

\begin{tabular}{lcccc}
\hline Variável & \multicolumn{3}{c}{ Categoria Profissional } \\
Setor & $\begin{array}{c}\text { Auxiliar de } \\
\text { enfermagem } \\
\mathbf{n}(\%)\end{array}$ & $\begin{array}{c}\text { Técnico de } \\
\text { enfermagem } \\
\mathbf{n}(\%)\end{array}$ & $\begin{array}{c}\text { Enfermeiro } \\
\mathbf{n}(\boldsymbol{\%})\end{array}$ & Total \\
\hline Ambulatório & $0(0)$ & $5(55,6)$ & $4(44,4)$ & 9 \\
Clínica médica & $3(18,8)$ & $9(56,2)$ & $4(25)$ & 16 \\
Clínica cirurgica & $0(0)$ & $9(1)$ & $0(0)$ & 9 \\
Centro cirurgico & $1(14,3)$ & $5(71,4)$ & $1(14,3)$ & 7 \\
UTI adulto* & $0(0)$ & $10(62,5)$ & $6(37,5)$ & 16 \\
UTI pediatrica & $2(11,1)$ & $7(38,9)$ & $9(50)$ & 18 \\
PS adulto** & $1(5,3)$ & $13(68,4)$ & $5(26,3)$ & 19 \\
PS pediátrico & $1(14,3)$ & $5(71,4)$ & $1(14,3)$ & 7 \\
Pediatria & $1(12,5)$ & $4(50)$ & $3(37,5)$ & 8 \\
Endoscopia & $1(25)$ & $1(25)$ & $2(50)$ & 4 \\
Hemodiálise & $0(0)$ & $2(40)$ & $3(60)$ & 5 \\
Maternidade & $0(0)$ & $2(50)$ & $2(50)$ & 4 \\
Centro Obstétrico & $0(0)$ & $1(100)$ & $0(0)$ & 1 \\
Berçário & $0(0)$ & $10(66,7)$ & $5(33,3)$ & 15 \\
Radiologia & $0(0)$ & $3(100)$ & $0(0)$ & 3 \\
Hospital Dia & $0(0)$ & $1(100)$ & $0(0)$ & 1 \\
\hline * Unidade de terapia intensiva*** Pronto Socorro & & &
\end{tabular}

Tabela 6. Classificação da amostra de profissionais de enfermagem alocados em unidades críticas e não críticas no Hospital Universitário da USP. São Paulo, 2015.

\begin{tabular}{lccc}
\hline Variável & \multicolumn{3}{c}{ Categoria Profissional } \\
\hline & $\begin{array}{c}\text { Auxiliar de } \\
\text { enfermagem }\end{array}$ & $\begin{array}{c}\text { Técnico de } \\
\text { enfermagem }\end{array}$ & Enfermeiro \\
\hline & $\mathbf{n}(\boldsymbol{\%})$ & $\mathbf{n}(\boldsymbol{\%})$ & $\mathbf{n}(\boldsymbol{\%})$ \\
\hline Unidade Crítica* & $4(6,2)$ & $39(60)$ & $22(33,8)$ \\
Unidade não Crítica** & $6(7,8)$ & $48(62,3)$ & $23(29,9)$ \\
\hline * Unidade de Terapia Intensiva adulto e pediátrica, Pronto Socorro adulto e pediátrico, Centro cirúrgico e \\
\multicolumn{4}{l}{ Obstétrico. ** Demais unidades. }
\end{tabular}

\subsection{CARACTERIZAÇÃO DO RITMO E PADRÃO DE SECREÇÃo CORTISOL}

Para análise do ritmo de secreção de cortisol, foi considerada a média da concentração de cortisol secretado ao longo dos dois dias nos períodos pré-determinados (ao acordar, 30 
minutos após acordar, às $14 \mathrm{~h}$, às $16 \mathrm{~h}$ e a noite ao dormir), bem como a classificação do ritmo em padrão típico e atípicos de cortisol, sendo que o atípico poderia ser "flat" ou inconsistente.

Na figura 6, observa-se a curva do ritmo diurno de concentração média de cortisol ao longo dos dois dias de coleta, no qual as concentrações em todos os períodos foram diferentes da concentração ao acordar ( $\mathrm{p}<0,01)$. A AUC total revelou que, em média, os profissionais secretaram 203,97 $\mu \mathrm{g} / \mathrm{dL}(\mathrm{DP} \pm 75)$ de cortisol ao longo do dia. Somente durante o período da manhã (CAR) foi observada secreção média de 12,7 $\mu \mathrm{g} / \mathrm{dL}(\mathrm{DP} \pm 5,03)$, com um aumento de 82,9\% na concentração de cortisol 30 minutos após acordar em relação à concentração imediatamente ao acordar.

Figura 6. Ritmo de secreção de cortisol ao longo do dia na amostra de profissionais de enfermagem do Hospital Universitário da USP. São Paulo, 2015.

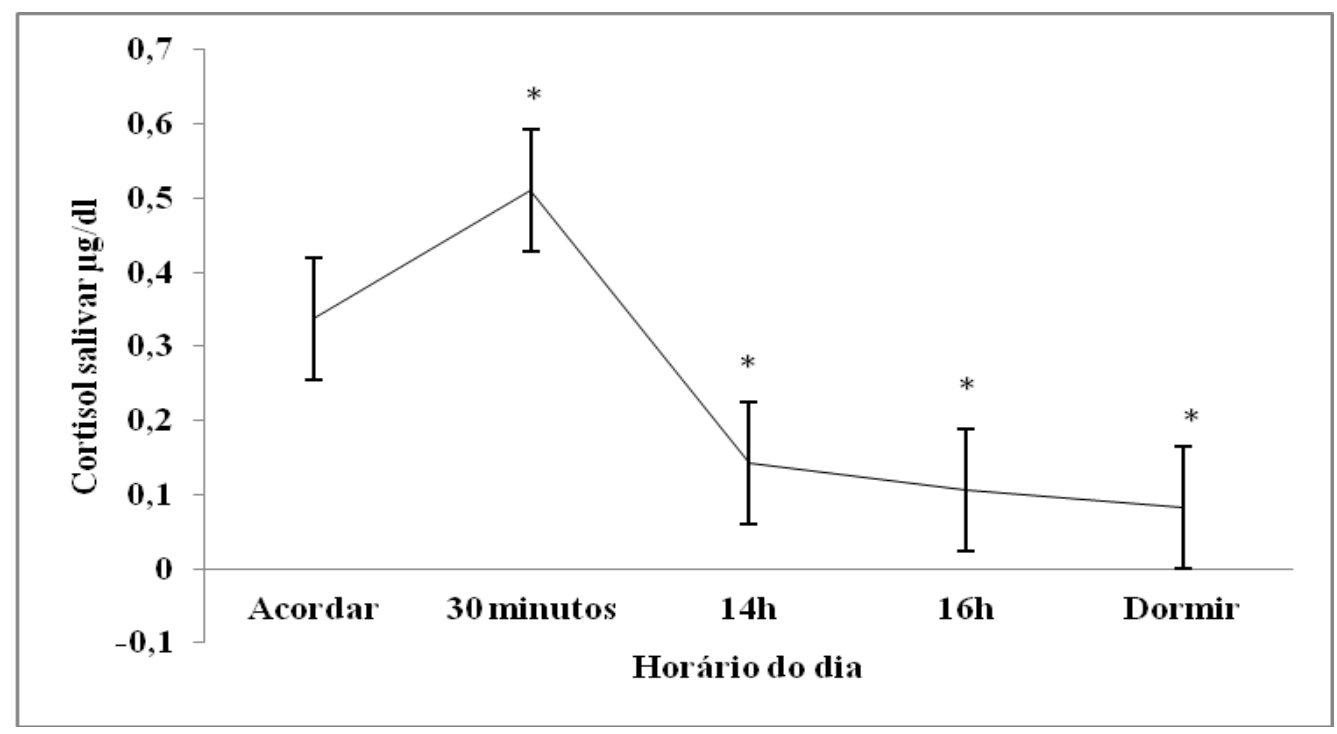

* Indica diferença significativa entre o cortisol ao acordar e o cortisol nos tempos 30' após acordar, 14h, 16h e ao dormir $(\mathrm{p}<0,05)$. As barras representam erro padrão. ANOVA para medidas repetidas, post hoc com teste Bonferroni.

Foi observada interação Tempo x Sexo na concentração de cortisol ao longo do dia $(\mathrm{F}(3,42)=3,2 ; \mathrm{p}=0,02)$, sendo que as mulheres apresentaram concentração de cortisol maior 30 minutos após acordar $(\mathrm{p}=0,017)$ e à noite em relação aos homens $(\mathrm{p}<0,001)$. (Figura 7). 
Figura 7. Ritmo de secreção de cortisol ao longo do dia e o sexo na amostra de profissionais de enfermagem do Hospital Universitário da USP. São Paulo, 2015.

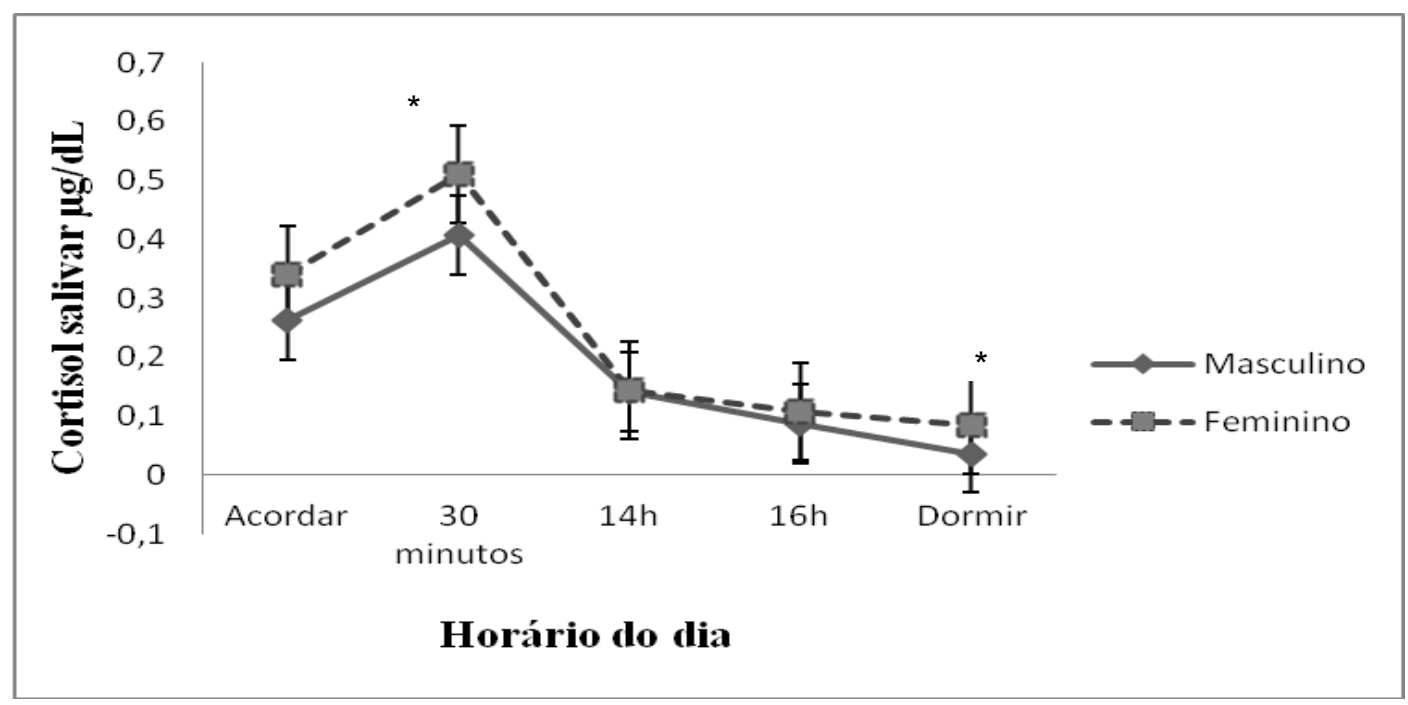

* Indica diferença significativa entre o cortisol ao acordar e o cortisol ao dormir $(\mathrm{p}<0,05)$ entre homens e mulheres. As barras representam erro padrão. ANOVA para medidas repetidas, post hoc com teste T-Student.

Não foi observada interação ou efeito dos demais dados sociodemográficas (idade, escolaridade) e antecedentes de saúde (doença crônica, uso de anticoncepcional, qualidade do sono e período do ciclo menstrual) na concentração de cortisol $(\mathrm{p} \geq 0,10)$. Também não foi observada influência do horário em que o participante acordou $(\mathrm{p}=0,7)$ ou foi dormir $(\mathrm{p}=$ 0,118 ) na na concentração média de cortisol.

Classificando o ritmo de secreção de cortisol ao longo do dia, observou-se que 29,2\% $(n=35)$ dos trabalhadores possuíam padrão "inconsistente"e 1,7\% (n=2) padrão "flat", ou seja, $31 \%$ dos trabalhadores apresentaram padrão atípico de secreção de cortisol. (Figura 8). 
Figura 8. Classificação da amostra de profissionais de enfermagem do Hospital Universitário da USP segundo padrão de secreção de cortisol. São Paulo, 2015.

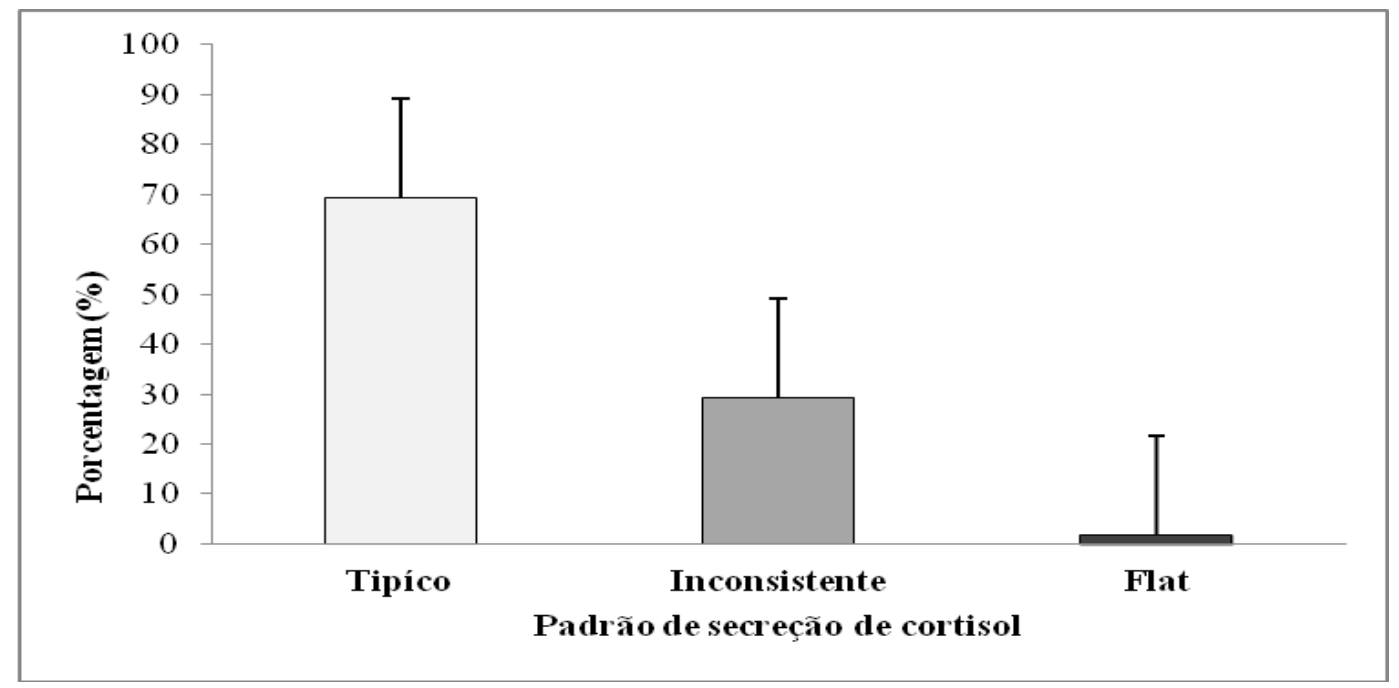

As barras representam erro padrão.

Em relação à concentração de cortisol, foi observada interação Tempo x Padrão da secreção de cortisol $(\mathrm{F}(7,415)=5,3 ; \mathrm{p}<0,001)$, sendo que os participantes com padrão "flat" apresentaram concentração de cortisol ao acordar e 30 minutos após acordar menor que os participantes com padrão “inconsistente" (acordar $p=0,002 ; 30$ 'após $p=0,046)$ e "típico" (acordar $\mathrm{p}=0,003 ; \mathrm{p}=0,038$ ). Além disso, os indivíduos do padrão inconsistente apresentaram concentração de cortisol ao dormir maior do que os participantes do grupo típico ( $p=0,01$; figura 9). 
Figura 9. Média da concentração de cortisol ao longo do dia segundo padrão de secreção na amostra de profissionais de enfermagem do Hospital Universitário da USP. São Paulo, 2015.

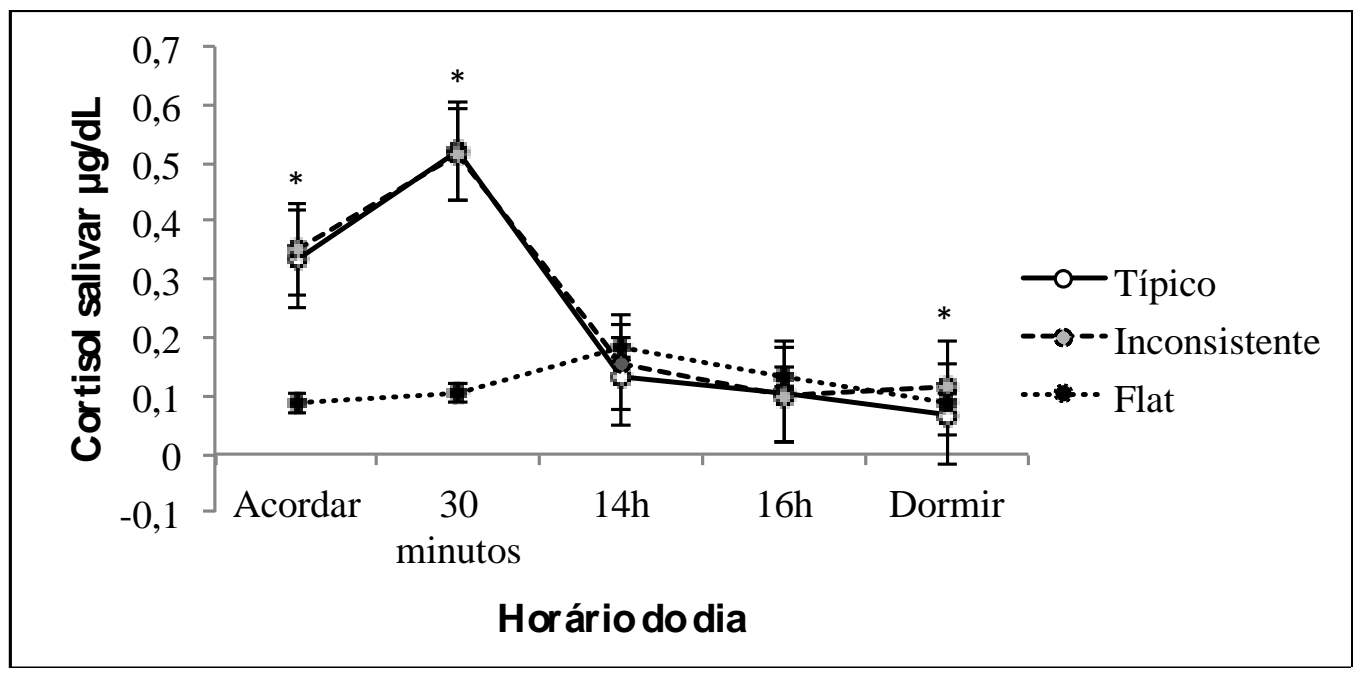

* Indica diferença significativa entre o cortisol ao acordar, 30 minutos após acordar e o cortisol ao dormir (p < $0,05)$ entre os participantes com padrão flat, inconsistente e típico. As barras representam erro padrão. ANOVA para medidas repetidas, post hoc com teste Bonferroni.

\subsection{CARACTERIZAÇÃO DA CARGA ALOSTÁTICA}

O percentual da carga alostática elevada encontrado no presente estudo foi de $47,2 \%$.

Na tabela 7. Observa-se o padrão de distribuição dos biomarcadores analisados para o cálculo do índice de carga alostática.

\begin{tabular}{|c|c|c|c|c|c|}
\hline Biomarcadores & $\begin{array}{c}\text { Valores de } \\
\text { referência }(\mathrm{SI})\end{array}$ & $\begin{array}{c}\text { Média } \\
(\mathrm{DP} \pm)\end{array}$ & $25^{\circ}$ Percentil & $\begin{array}{c}\mathbf{7 5}^{\circ} \\
\text { Percentil }\end{array}$ & $\begin{array}{c}\text { Risco } \\
\text { elevado } \\
\text { n( }(\%)\end{array}$ \\
\hline Fibrinogênio g/L & $1,8-4,0$ & 3,4 & 2,35 & $3,45^{*}$ & $\begin{array}{c}64 \\
(46,4)\end{array}$ \\
\hline $\begin{array}{l}\text { Proteína } \mathrm{C} \text { reativa } \\
\mathrm{nmol} / \mathrm{L}\end{array}$ & 28,57 & 33,641 & 7,14 & $21,43^{*}$ & $\begin{array}{c}28 \\
(20,4)\end{array}$ \\
\hline $\begin{array}{l}\text { Hemoglobina glicada } \\
(\%)\end{array}$ & $0,0460-0,0620$ & 5,411 & 1,625 & $4,875^{*}$ & $\begin{array}{c}35 \\
(26,1)\end{array}$ \\
\hline DHEA-S mmol/L & $\begin{array}{c}\text { Masc. 0,94-15,36 } \\
\text { Fem. 0,70-12,42 }\end{array}$ & 3,322 & $\begin{array}{l}\text { Masc. } 4,54 * \\
\text { Fem. 3,63* }\end{array}$ & $\begin{array}{c}\text { Masc. } 11,76 \\
\text { Fem. } 8,79\end{array}$ & $\begin{array}{c}89 \\
(64,5)\end{array}$ \\
\hline $\begin{array}{l}\text { Cortisol plasmático } \\
\mathrm{nmol} / \mathrm{L}\end{array}$ & $118,63-618,01$ & 375,091 & 243,48 & $491,17 *$ & $\begin{array}{c}28 \\
(20,4)\end{array}$ \\
\hline Colesterol total $\mathrm{mmol} / \mathrm{L}$ & $<5,17$ & 4,913 & 1,552 & $4,65^{*}$ & 78 \\
\hline
\end{tabular}




\begin{tabular}{lccccc} 
HDL colesterol mmol/L & $>1,55$ & 1,456 & $0,2575^{*}$ & 0,7725 & $(56,1)$ \\
PAS mmHg & $90-140$ & 123,47 & 102,5 & $127,50 *$ & 44 \\
& & & & & $(33,3)$ \\
PAD mmHg & $60-90$ & 81,92 & 67,5 & $82,50^{*}$ & 55 \\
Cintura/Quadril & $0,8-1$ & 0,8281 & 0,85 &, $095^{*}$ & $(41,7)$ \\
& & & & & $(59,7)$ \\
\hline
\end{tabular}

Os dados foram convertidos na unidade de referência nacional para unidades internacionais conforme apêndice B. * Significa o percentil 25 e 75.

Quanto às variáveis sociodemográficas, somente a idade influenciou a carga alostática. Os trabalhadores com carga alostática elevada eram mais velhos (média $=41,8 ; \mathrm{DP} \pm 8,9$ ) comparados aos trabalhadores com carga alostática baixa (média 37,6; DP \pm 9,8; $\mathrm{p}=0,009$ ). Não houve associação entre o sexo e carga alostática $(p=0,411)$.

No tocante aos antecedentes de saúde, não houve influência das doenças crônicas na carga alostática $(\mathrm{p}>0,116)$.

\subsection{ASSOCIAÇÃO ENTRE AS CARACTERÍSTICAS DE REGIME DE TRABALHO E O PADRÃO DE SECREÇÃO DE CORTISOL E A CARGA ALOSTÁticA.}

Não foi observada influência da categoria profissional $\left(\chi^{2}=2,9 ; \mathrm{p}=0,570\right)$, turno $\left(\chi^{2}=\right.$ $2,1 ; \mathrm{p}=0,346)$, unidade $\left(\chi^{2}=1,9 ; \mathrm{p}=0,384\right)$, tempo na profissão $(\mathrm{F}(2,111)=1,1 ; \mathrm{p}=0,337) \mathrm{e}$ tempo de trabalho no $\mathrm{HU}(\mathrm{F}(2,111)=1,4 ; \mathrm{p}=0,244)$ no padrão de secreção de cortisol. 
Figura 10. Padrão de secreção de cortisol segundo tempo na profissão e tempo de trabalho no Hospital Universitário (A), categoria profissional (B), turno de trabalho (C) e Unidade de atendimento (D).
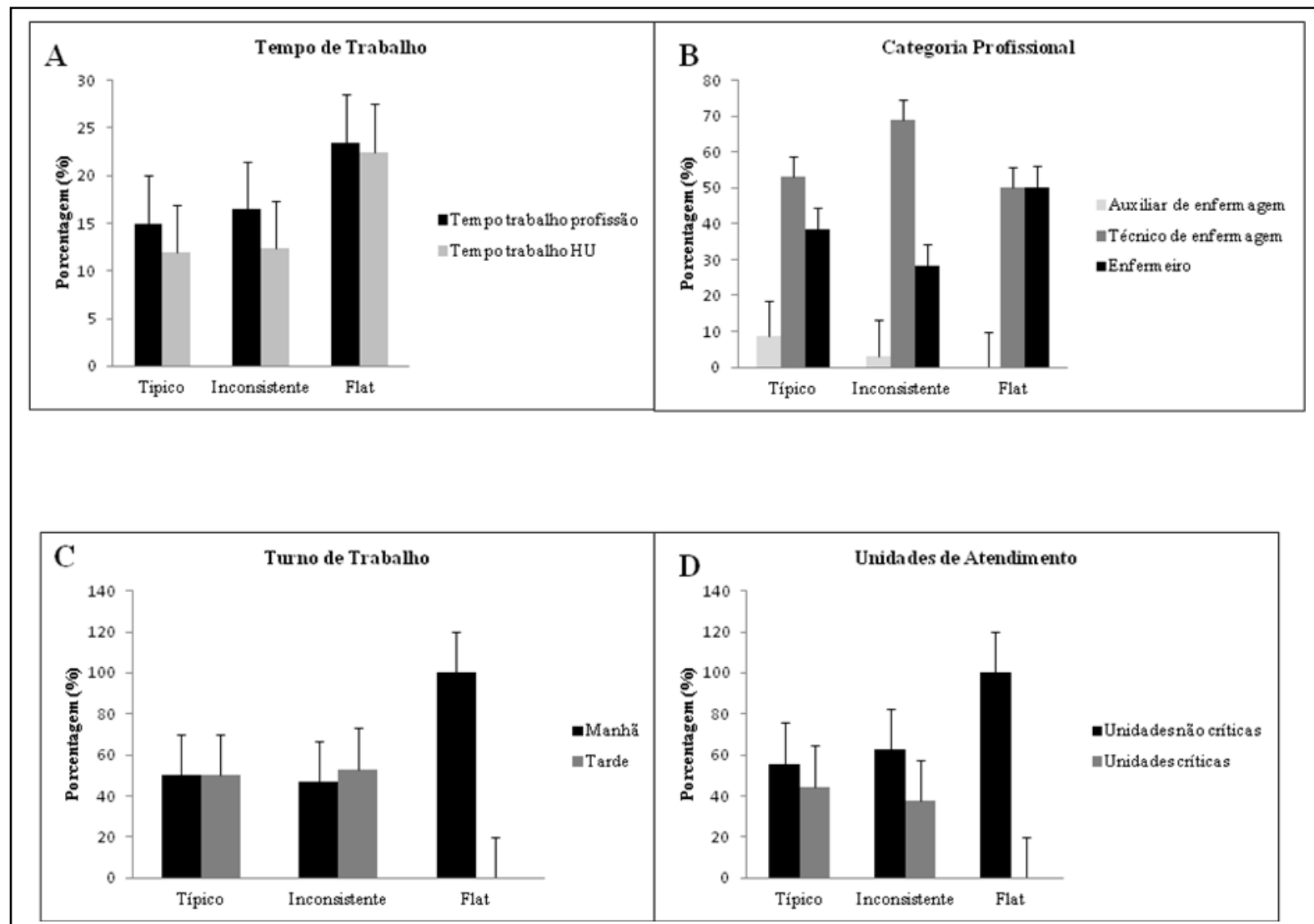

As barras representam erro padrão. Teste qui-quadrado.

Não foi observada influência da categoria profissional $\left(\chi^{2}=2,9 ; \mathrm{p}=0,231\right)$, turno $\left(\chi^{2}=\right.$ $0,9 ; \mathrm{p}=0,488)$ e unidade de atendimento $\left(\chi^{2}=0,1 ; \mathrm{p}=0,523\right)$ na intensidade da carga alostática (Figura 11). 
Figura 11. Intensidade da carga alostática segundo categoria profissional (A), turno de trabalho (B) e Unidade de atendimento (C).

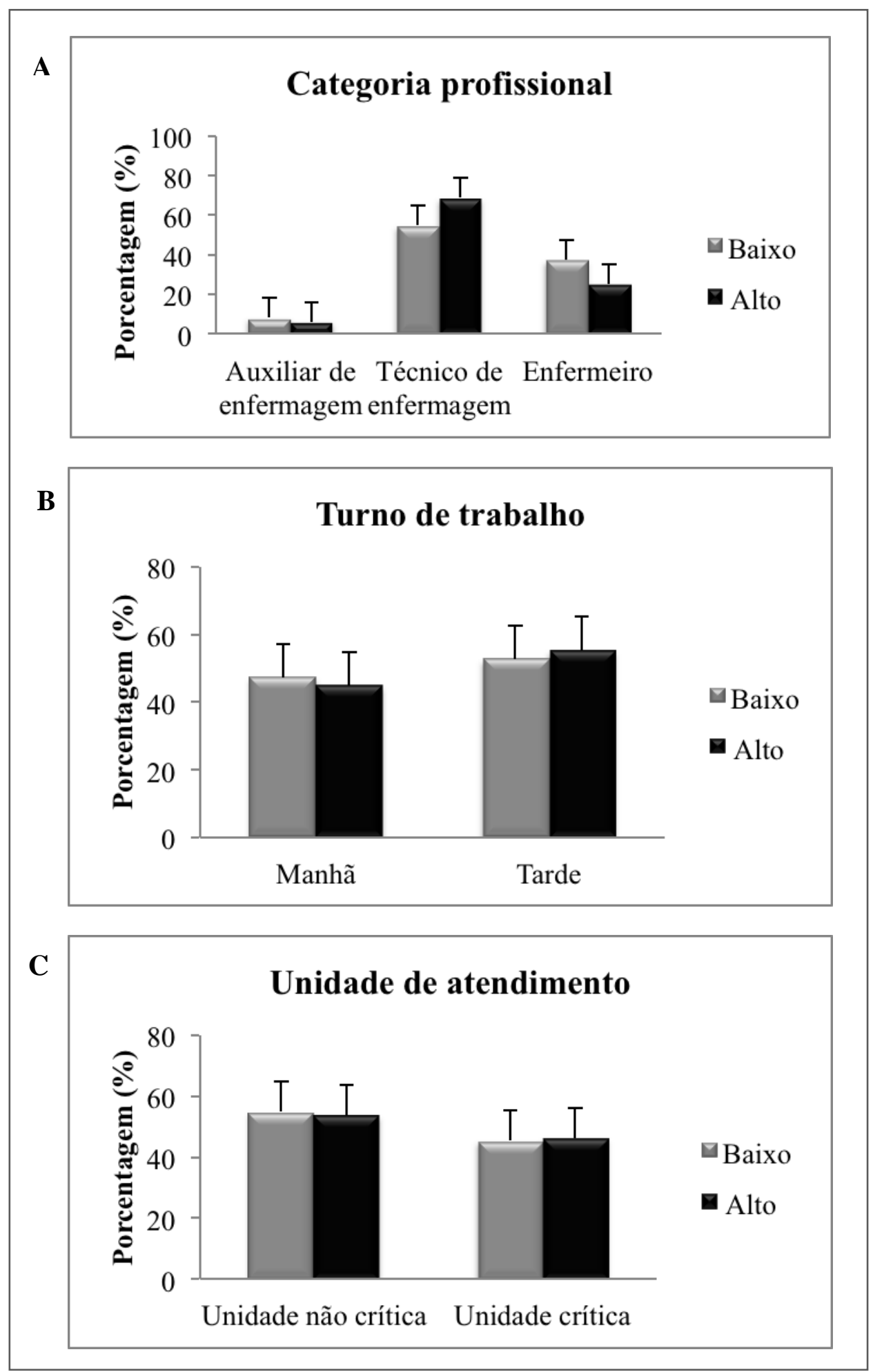

As barras representam erro padrão. Teste qui-quadrado. 
Foi observado que quanto maior o tempo de trabalho na profissão, maior o índice de carga alostática $(\mathrm{p}<0,05)$. Entretanto, na análise de regressão multivariada, tendo as variáveis idade, tempo de trabalho na profissão e tempo de trabalho no HU, não foi observada influência das características de trabalho no índice de carga alostática $(\mathrm{p} \geq 0,185)$.

\subsection{ASSOCIAÇÃO ENTRE O PADRÃO DE SECREÇÃO DE CORTISOL E CARGA ALOSTÁTICA}

Não houve associação entre o padrão de secreção de cortisol e a intensidade da carga alostática $\left(\chi^{2}=1,2 ; p=0,557 ;\right.$ Figura 12$)$.

Figura 12. Porcentagem do padrão de secreção cortisol segundo intensidade da carga alostática da amostra de profissionais de enfermagem do Hospital Universitário. São Paulo,2015.

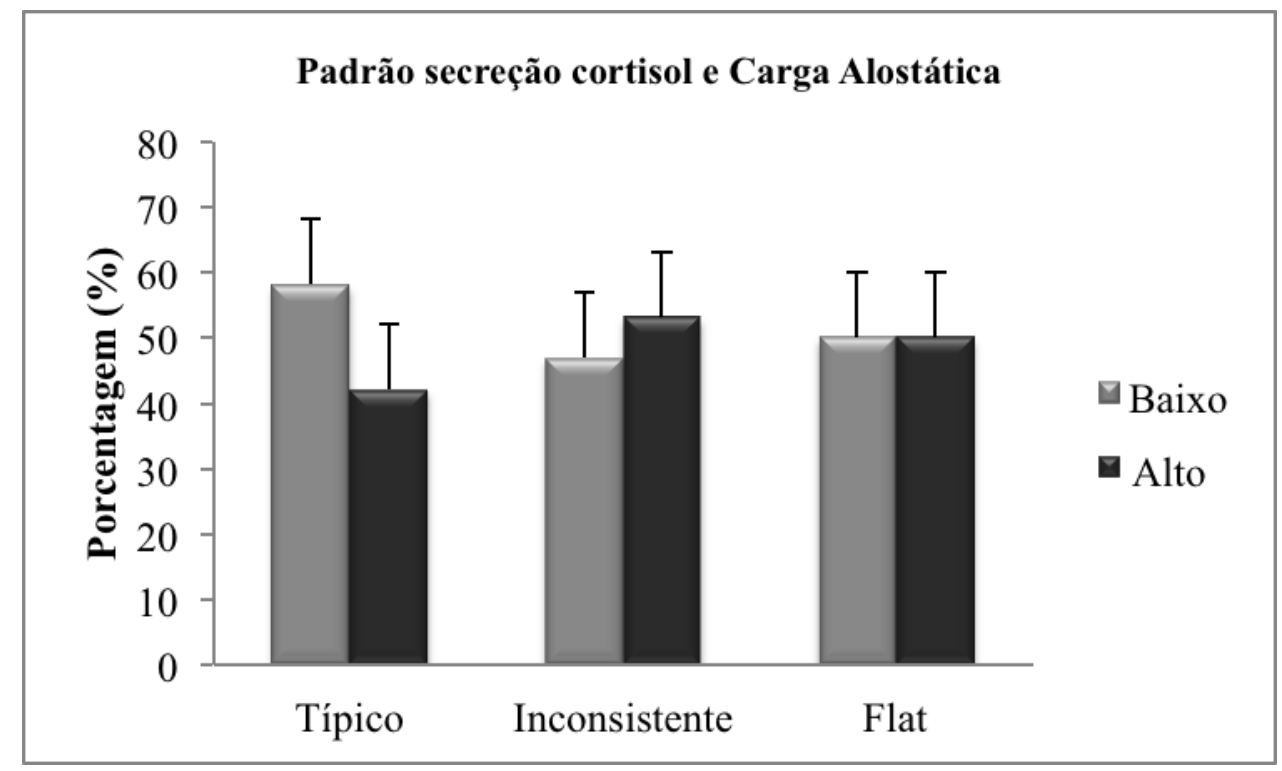

As barras representam erro padrão. Teste Qui-quadrado.

Também não foi observada interação $(F(3,382)=1,02 ; \mathrm{p}=0,389)$ ou efeito da carga alostática na concentração de cortisol ao longo do dia $(F(1,113)=1,5 ; p=0,223$, Figura 13). 
Figura 13. Ritmo de secreção de cortisol ao longo do dia em relação à intensidade da carga alostática.

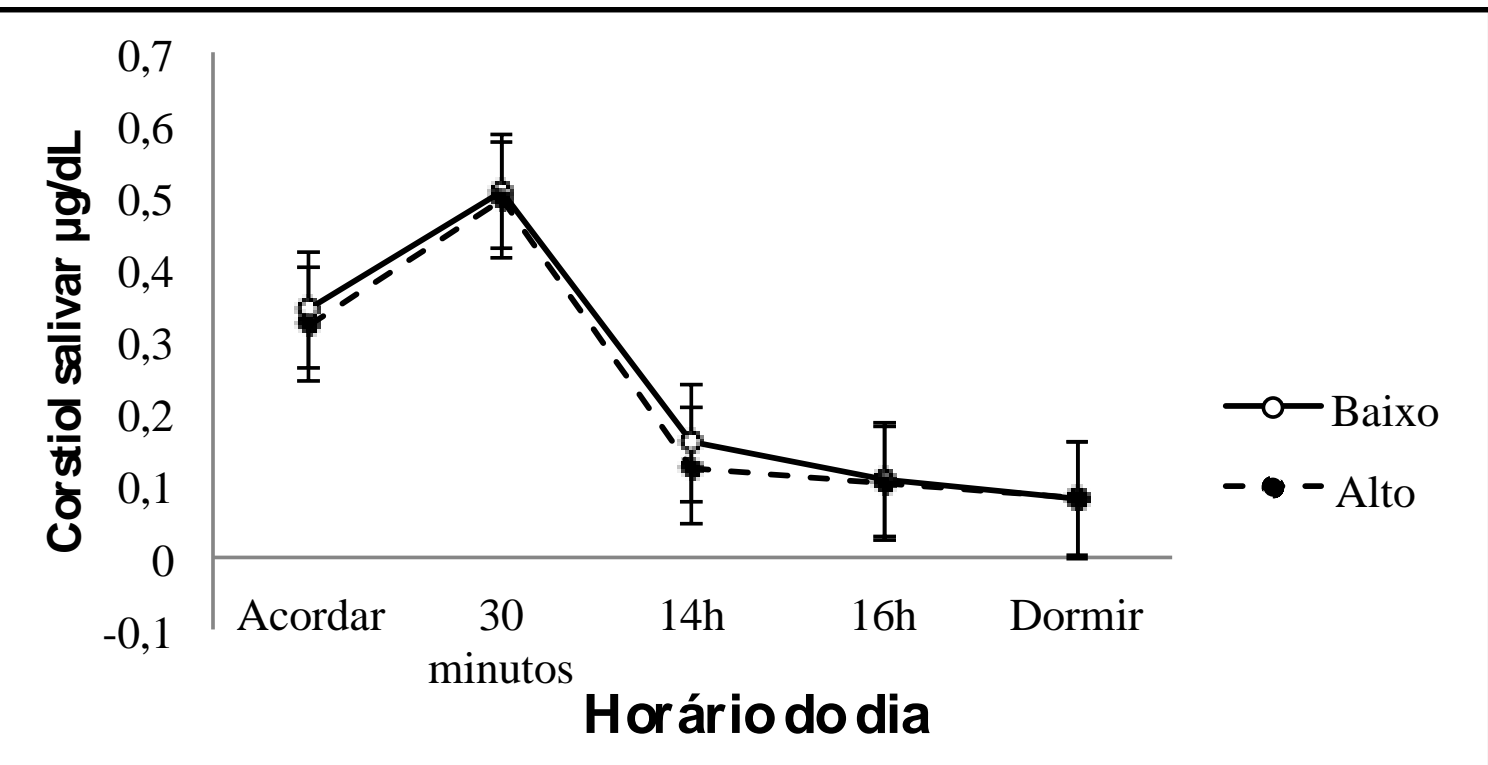

As barras representam o erro padrão. ANOVA para medidas repetidas.

Não houve correlação entre as concentrações de cortisol pela manhã (CAR r = -0,103; $\mathrm{p}=0,275$ ) e ao longo do dia (AUC total $\mathrm{r}=0,08 ; \mathrm{p}=0,52$ ) no índice de carga alostática. 
DISCUSSÃO 


\section{DISCUSSÃO}

A discussão dos resultados está organizada seguindo a apresentação dos dados, conforme segue: caracterização sociodemográfica da amostra, ritmo de secreção cortisol, caracterização da carga alostática, associação entre o padrão de secreção de cortisol e a carga alostática.

\subsection{CARACTERIZAÇÃO SOCIODEMOGRÁFICA DA AMOSTRA}

Corroborando com o perfil sociodemográfico dos profissionais de enfermagem no Brasil, a amostra do presente estudo foi constituída predominantemente por profissionais do sexo feminino, adultos jovens e pertencentes em sua grande maioria à categoria técnico de enfermagem. Segundo os dados do Conselho Federal de enfermagem (COFEN) ${ }^{51}$, atualmente, os profissionais de enfermagem são em sua maioria do sexo feminino (87,24\%), e concentram-se predominantemente na faixa etária de 26 a 35 anos. Ainda segundo o COFEN, quase metade dos profissionais de enfermagem pertencem à categoria de técnico de enfermagem $(45,5 \%)$.

Em relação ao nível socioeconômico, segundo dados do Instituto de Pesquisa Econômica Aplicada - IPEA ${ }^{52}$, entre 2009 e 2012, a enfermagem foi considerada uma das carreiras com maior geração de postos de trabalho, o que pode explicar o predomínio de profissionais do presente estudo alocados no nível econômico B.

No tocante ao perfil de comorbidades, dos poucos profissionais que possuíam doenças crônicas, a hipertensão arterial foi a afecção predominante. Corroborando este achado, estudo conduzido com profissionais de enfermagem no Brasil identificou que aproximadamente $21 \%$ da amostra investigada possuía hipertensão arterial, além de estresse elevado ${ }^{53}$.

\subsection{RITMO DE SECREÇÃO DE CORTISOL}

Confirmando a hipótese inicial do presente estudo, observou-se que mais de um quarto dos profissionais de enfermagem apresentaram padrão atípico (inconsistente e "flat") de secreção diurna de cortisol. Sendo que os participantes com padrão "flat" apresentaram 
concentração de cortisol pela manhã menor que os participantes com padrão "inconsistente" e "típico". Os indivíduos do padrão inconsistente apresentaram concentração de cortisol ao dormir maior do que os participantes do grupo típico. Sob condições fisiológicas, a secreção de cortisol possui regulação circadiana, com concentrações elevadas pela manhã e pico 30 minutos após acordar, declínio gradual à tarde e concentrações mais baixas à noite ${ }^{54}$. Alterações neste padrão de secreção são sugestivas de sobrecarga alostática. Considerando isso, uma possível explicação para a ocorrência de padrões atípicos de secreção de cortisol nos profissionais do presente estudo, além de uma hiporresponsividade de cortisol ao despertar pode estar relacionada à carga de trabalho ${ }^{22}$.

Fundamentando esta hipótese, evidências obtidas com uma amostra de soldados, revelaram que aqueles com burnout (síndrome relacionada ao estresse no trabalho) apresentaram padrão "flat" de secreção diurna de cortisol, com concentrações mais baixas pela manhã e mais elevadas à noite ${ }^{55}$. Em contrapartida, participantes saudáveis com características sociodemográficas semelhantes as do presente estudo (adultos jovens e mulheres), apresentaram padrão atípico de secreção de cortisol somente em 17\% da amostra, valor, este, bastante inferior ao do presente estudo ${ }^{56}$. Já em estudos envolvendo análise do ritmo de secreção de cortisol em idosos saudáveis ou com queixas subjetivas de memória e depressão foi verificado que $48 \%$ apresentaram padrão de secreção inconsistente e $2 \%$ apresentaram padrão "flat" profissionais de enfermagem, os autores concluem que os achados podem refletir uma variabilidade no ritmo de secreção de cortisol decorrente do envelhecimento ${ }^{7}$ ou em função da ocorrência de alterações cognitivas ou emocionais ${ }^{57}$. Neste sentido, considerando que a amostra foi composta predominantemente por profissionais de enfermagem adultos jovens, pode-se entender que o percentual elevado de atípicos no padrão de secreção de cortisol pode representar uma alteração gerando repercussões negativas de natureza cognitiva ou psiquiátricas.

Outro achado interessante do presente estudo foi a observação de que os profissionais de enfermagem apresentaram aumento superior à 82\% na concentração de cortisol 30 minutos após acordar em relação à concentração imediatamente ao acordar, com concentração média ao longo do dia igual a 203,97 $\mu \mathrm{g} / \mathrm{dL}$. Fisiologicamente, a resposta de cortisol ao acordar (cortisol awakening response - CAR) é caracterizada por um aumento entre 38 a 75\%, com média igual a 50\%, na concentração de cortisol ao despertar, mesmo nos dias de trabalho ${ }^{58}$. O aumento do cortisol pela manhã está relacionado ao processo de despertar, através da ativação 
de representações de memórias sobre tempo e espaço que tem potencial para estimular a atividade do eixo HPA e preparar o indivíduo para as demandas cotidianas do dia ${ }^{59}$. Assim, a CAR representa uma resposta adaptativa do organismo, mobilizando-o para que este saia do status de repouso para o de ação e o prepare para enfrentar os desafios do dia ${ }^{60,61}$. Neste contexto, o aumento de $82 \%$ na CAR nos profissionais de enfermagem poderia ser interpretado como uma resposta benéfica e adaptativa, preparando-os para os desafios relacionados às atividades do trabalho. Entretanto, ao comparar nosso percentual com o percentual descrito na população geral e mesmo em trabalhadores de outras áreas ${ }^{58,60,61,62}$, verificamos que o percentual de elevação da CAR, no presente estudo, está acima do limite máximo considerado fisiologicamente esperado ${ }^{59}$, sugerindo novamente que estes profissionais podem estar sob estresse crônico representado em uma hiperresponsividade do eixo HPA ao despertar. Sustentando esta interpretação, em profissionais da área administrativa, respostas aumentadas de cortisol ao despertar foram associadas às demandas intensas de trabalho ${ }^{63}$. Em professores do nível médio de ensino, foi observado que quanto maior a tensão no trabalho, maior a concentração de cortisol no inicio do dia ${ }^{64}$. Especificamente na enfermagem, foi observado que enfermeiros com demanda de trabalhado elevada e menor controle exercido pelo trabalhador apresentavam maior percentual de cortisol elevado $^{65,66}$. Em enfermeiras japonesas, concentrações elevadas de cortisol se associaram com maior preocupação quanto à falta de recursos no trabalho, conflitos com colegas e medo de demissão ${ }^{67}$. Além disso, sabe-se que concentração da fração livre de cortisol aumenta rapidamente durante a primeira hora ao despertar e que a magnitude da resposta e tempo de curso da concentração do cortisol salivar após o despertar estão significativamente relacionadas com vários fatores psicológicos como por exemplo o estresse crônico ${ }^{68}$.

De fato, a carga de trabalho, conflitos internos entre a equipe, a indefinição de papel e a falta de respaldo do profissional estão entre os principais estressores na atividade dos profissionais de enfermagem ${ }^{30,69}$. Os trabalhadores de enfermagem estão expostos a uma ampla variedade de cargas de trabalho, geradoras de processos de desgaste que podem comprometer a qualidade de vida no trabalho ${ }^{70,71}$. As cargas de trabalho são elementos do processo de trabalho que interagem dinamicamente entre si e o corpo do trabalhador, estão demonstradas na somatização de algumas experiências que se manifestam de forma física ou psicológica ou pelas desordens psicoemocionais como angústia, falta de motivação e medo ${ }^{72}$. 
Estas cargas de trabalho, por sua vez, estão associadas a ocorrência de doenças crônicas de natureza cardiovascular ${ }^{73}$, osteomuscular, transtornos mentais e comportamentais, bem como distúrbios do sono ${ }^{74,75}$.

Embora o percentual de profissionais com padrão atípico não tenha sido elevado o que pode refletir um perfil de adaptação ou preparo deste trabalhador para sua atividade de enfermagem pela hiperresponsividade do eixo HPA ao despertar sinalizando, que estes trabalhadores estão em situação de sobrecarga de estresse. Entretanto outra possível explicação para o observação destes achados, pode estar relacionada as diferenças de sexo e idade. Em relação ao sexo, estudos mostram que homens tem concentração maior de cortisol do que as mulheres e, que isto está associada a menor concentração da globulina de ligação ao cortisol $(\mathrm{CBG})$ nos homens em relação as mulheres ${ }^{76}$. No presente estudo, observamos o contrário, as mulheres apresentaram uma concentração de cortisol maior pela manhã do que nos homens, reforçando a interpretação de que os achados obtidos podem refletir uma situação de sobrecarga de estresse, já que seria esperado uma menor concentração de cortisol nas mulheres. Em relação à influência da idade, somente indivíduos mais velhos (acima de 60 anos) apresentam concentrações maiores de cortisol do que os adultos jovens. Dentro da faixa etária do adulto, a mesma observada na amostra de profissionais de enfermagem, não há diferença significativa na concentração de cortisol ${ }^{77,78}$. Assim, a idade não parece explicar nem o percentual de atípicos na secreção diurna de cortisol, tampouco a hiporresponsividade do eixo HPA ao acordar.

Diante do exposto, o percentual de profissionais de enfermagem com padrão atípico de secreção de cortisol, bem como a hiperresposta de CAR sugere que estes trabalhadores podem estar sob sobrecarga de estresse, suscitando a reflexão sobre as consequências que isto pode trazer ao longo do tempo para a saúde do trabalhador.

Cabe ressaltar que esta interpretação seria reforçada a partir de evidências a respeito do quanto o profissional atribui seu estresse à sobrecarga no trabalho e quais manifestações comportamentais, físicas e emocionais relacionados ao estresse, estes trabalhadores apresentam. Assim, recomenda-se em estudos futuros a investigação destes fatores. 


\subsection{CARGA ALOSTÁTICA NOS PROFISSIONAIS DE ENFERMAGEM}

Confirmando a hipótese de que os profissionais de enfermagem estão sob carga alostática, evidenciamos que quase metade da amostra apresentou carga alostática elevada, reforçando novamente a interpretação de que as demandas do trabalho podem justificar esse percentual.

Estudos anteriores demonstram associação entre estresse relacionado ao trabalho e nível elevado de carga alostática ${ }^{48,79,80,81}$. Em um grupo de professoras, foi observado que quanto maior o desequilibrio esforço-recompensa nas atividades de trabalho, a exaustão vital e emocional, maior o índice de carga alostática ${ }^{79}$. Outro estudo realizado com trabalhadores de diferentes áreas evidenciou associação significativa entre maior carga alostática, maior nível de percepção de estresse e sintomas de burnout ${ }^{48}$. Em trabalhadores da indústria, foi observado carga alostática elevada nos profissionais com controle inferior do trabalho ${ }^{80}$ e maior demanda de atividades ${ }^{82}$. Em profissionais da área de saúde pública com sintomas de fadiga apresentaram níveis mais elevados carga alostática ${ }^{83}$. Além disso, trabalhadores jovens com maior instabilidade na carreira apresentaram risco três vezes maior de desenvolver carga alostática elevada e sintomas psicossomáticos ${ }^{81}$.

Em conjunto, esses achados evidenciam a relação entre carga alostática e estresse no trabalho, reforçando a idéia de que o percentual elevado de profissionais de enfermagem com carga alostática elevada observado no presente estudo pode estar associado às demandas cotidianas do trabalho.

Além disso, ao comparamos o percentual de carga alostática do presente estudo com os obtidos em indivíduos da população geral $(40 \%)^{48}$ há mais indivíduos entre os profissionais de enfermagem com carga alostática elevada do que os indivíduos na população geral, reforçando a ideia de que possivelmente pode ser a carga de trabalho que explica os achados do presente estudo. Entretanto, há que se destacar que embora, diferenças nas características da amostra pudessem explicar o resultado encontrado, estudos de revisão mostram que a carga alostática é maior em indivíduos mais velhos e com nível socioeconômico baixo ${ }^{19,84}$. No presente estudo, além da amostra ser predominantemente composta por profissionais adultos jovens e com nível social médio, exceto pela idade, não observamos efeito das características sociodemográficas e antecedentes de saúde no índice de carga alostática. 
Assim, torna-se razoável assumir que o percentual elevado de carga alostática observado nestes profissionais podem ser decorrentes da exposição repetitiva e prolongada destes trabalhadores às demandas e cargas cotidianas de trabalho.

Em conjunto, esses achados sugerem um elevado risco para o adoecimento por doenças relacionadas ao estresse, principalmente as de natureza cardiovascular, imunológicas e psiquiátricas. Diversos estudos têm demonstrado o elevado poder preditor de morbidade e mortalidade baseado no índice de carga alostática ${ }^{19}$, reforçando o potencial risco aos quais os profissionais de enfermagem estão expostos em função do estresse crônico relacionado ao trabalho. Neste sentido, destaca-se a necessidade de investigação de fatores de proteção (ex: vínculo parental, educação, suporte social, locais de trabalho saudáveis) nestes profissionais na tentativa de propor estratégias de controle e enfrentamento do estresse no trabalho para promoção da saúde dos trabalhadores.

\subsection{INFLUÊNCIAS DAS CARACTERÍSTICAS DO REGIME DE TRABALHO NO PADRÃO DE SECREÇÃo DE CORTISOL E NA CARGA ALOSTÁTICA}

Vários estudos conduzidos em primatas demonstraram associação significativa entre concentrações de cortisol e nível social em estruturas hierárquicas compostas por animais com posição dominante e subordinada. Animais subordinados apresentam concentrações mais elevadas de cortisol do que os animais dominantes, principalmente quando estão sujeitos diversos estressores ou quando vivenciam diminuição nas oportunidades de suporte social ${ }^{85}$. A carga alostática de subordinação depende principalmente de quanto os subordinados sofrem com ameaças físicas ou psicológicas provenientes dos dominantes, além da disponibilidade de mecanismos de enfrentamento ${ }^{86}$.

Dado que os profissionais de enfermagem estão organizados sob uma estrutura social hierárquica, na qual os enfermeiros desempenham o papel de líder (dominantes) e os técnicos e auxiliares de enfermagem ocupam a posição de subordinados, levantou-se a hipótese de que haveria diferença na concentração de cortisol entre estes trabalhadores. Entretanto, não observamos diferença no percentual de padrão atípico de secreção de cortisol tampouco de carga alostática elevada entre auxiliares, técnicos de enfermagem e enfermeiros. 
A maioria dos estudos sobre estresse ocupacional na enfermagem publicados em periódicos qualificados e dissertações de mestrado foram desenvolvidos com amostra compostas somente por enfermeiros ${ }^{4,5,30,32,43,53,87}$. O percentual de enfermeiros que referem nível elevado de estresse varia entre $14 \%$ a quase $80 \%$ nos diferentes estudos ${ }^{43,46,88,89}$. Dentre esses somente dois estudos ${ }^{43,46}$ analisaram concentrações de cortisol, mas nenhuma relação em relação à categoria profissional foi estabelecida, uma vez que a amostra foi composta somente por enfermeiros. Curiosamente, os estudos que abordam a equipe de enfermagem, incluindo os auxiliares e técnicos de enfermagem são escassos e não conduziram análises comparativas para verificar se as concentrações de cortisol eram maiores em uma categoria em detrimento da outra ${ }^{90,91,92}$. Corroborando nossos achados, Gouveia (2015) não identificou diferença significativa no percentual de estresse elevado entre auxiliares, técnicos de enfermagem e enfermeiros ${ }^{92}$. Entretanto, não há dados em relação à análise da concentração de cortisol entre estes profissionais.

Nossos achados revelam que a frequência de padrão atípico e o nível de carga alostática independe da categoria profissional, sugerindo que as relações de dominância ou subordinação não influenciam a manifestação dos mediadores biológicos do estresse crônico. Entretanto, é fundamental a investigação da percepção de estresse destes profissionais, bem como a qualidade das relações interpessoais para se analisar quais fatores mediadores ou moderadores podem influenciar estas relações a ponto de não exercer influência na expressão biológica do estresse crônico.

Outra hipótese levantada no presente estudo relacionada às características do trabalho, diz respeito ao exercício profissional em unidades de atendimento a pacientes críticos e não críticos. Hipoteticamente, dados o nível gravidade dos pacientes e, portanto a imprevisibilidade e pouco controle sobre a estabilidade e recuperação dos pacientes, seria esperado que os profissionais de enfermagem alocados nas unidades críticas tivessem maior percentual de padrões atípicos de secreção de cortisol e de carga alostática elevada. Entretanto, não foi observada associação entre estas variáveis.

Vários estudos contrariam estes dados, já que revelam níveis elevados de estresse percebido em profissionais de unidades de emergência e terapia intensiva 32,87,88,89,93. Entretanto, em todos estes estudos foram analisados fatores emocionais, comportamentais e de percepção de estresse nos profissionais. Em nenhum deles foi analisado mediadores biológicos da reação de estresse. 
Neste sentido, os dados do presente estudo sugerem que a manifestação biológica do estresse crônica não é influenciada pela unidade de atendimento em que o profissional trabalha. Na verdade, possivelmente a diferença não esteja gravidade do paciente, mas sim no processo de trabalho na qual os trabalhadores estão inseridos, nos recursos físicos, materiais e humanos disponíveis e nas relações interpessoais existentes. Estes fatores parecem influenciar muito mais a carga de trabalho o desenvolvimento do estresse crônico do que o fato de atender pacientes gravemente enfermos ou não. Neste sentido, sugere-se que estudos futuros analisem quais atividades os profissionais de enfermagem consideram mais estressantes ou desgastantes para verificar seu impacto na expressão biológica do estresse crônico nestes profissionais.

\subsection{ASSOCIAÇÃO ENTRE INTENSIDADE DA CARGA ALOSTÁTICA E PADRÃO DE SECREÇÃO DE CORTISOL ALTERADO}

Contrariando a hipótese de que os profissionais com padrão atípico de cortisol apresentam carga alostática maior do que os com padrão típico, não observamos associação entre estas variáveis (cortisol ao longo dia e carga alostática).

Alguns autores evidenciaram, em um grupo de trabalhadores da área da saúde, que entre aqueles com sintomas de burnout, o nível de carga alostática era maior ${ }^{48}$. Além disso, os que apresentaram carga alostática elevada possuíam um perfil de hiporresponsividade (compatível com padrão "flat") na secreção de cortisol ao acordar em comparação as que tinham carga alostática baixa ${ }^{48}$. Outros autores apontam associação significativa entre cortisol e percepção de estresse relacionado ao trabalho em profissionais de enfermagem. 94,95,96. Em contrapartida, outros autores não evidenciaram associação significativa entre o estresse no trabalho e concentrações de cortisol com um grupo de enfermeiros ${ }^{43}$. evidenciando que a confirmação da hipótese de que estas variáveis estão realmente associadas ainda se mantém em discussão.

A investigação sobre os mediadores biológicos da resposta de estresse em trabalhadores de enfermagem é relativamente recente, de modo que estes achados revelam a necessidade de investigar em amostras maiores e provenientes de diferentes centros de saúde 
para confirmar ou refutar a hipótese de que existem trabalhadores de enfermagem com carga alostática apresentam alterações no ritmo de secreção de cortisol.

As psicopatologias relacionadas ao trabalho em geral representam uma sobrecarga importante para os trabalhadores de maneira global. As estratégias de detecção são cruciais para o diagnóstico correto, manejo e estratégias de prevenção ${ }^{48}$.

\subsection{LIMITAÇÕES DO ESTUDO}

Embora no presente estudo tenham sido observados aspectos interessantes em relação ao padrão de secreção de cortisol e carga alostática nos profissionais de enfermagem, algumas limitações precisam ser consideradas na interpretação dos dados.

Primeiramente, não foram inseridas nas análises dados sobre a percepção de estresse dos profissionais, tampouco a satisfação de condições no trabalho, fatores estes que podem interferir na sobrecarga de estresse. Além disso, os resultados revelam padrões atípicos de secreção de cortisol e carga alostática de profissionais de enfermagem de um único hospital, comprometendo assim, a validade externa do estudo na capacidade de generalizar os dados para a população geral dos profissionais de enfermagem. O HU-USP apresenta características relacionadas ao regime de trabalho (jornada única, salário com média maior em relação aos outros hospitais, carga horária semanal, os profissionais de enfermagem residem próximo a redondeza do trabalho, ainda possuem autonomia para decisões importantes relacionadas a assistência) bastante peculiares e favoráveis ao processo de trabalho. Ao mesmo tempo que isto pode diferir da população geral dos profissionais de enfermagem alocados em outras instituições e em outras regiões do Brasil, assemelha-se à realidade internacional dos países desenvolvidos, no qual o cenário de trabalho é ainda mais favorável que o descrito neste estudo. Destaca-se, portanto, que mesmo diante de um cenário aparentemente mais favorável, um percentual significativo de trabalhadores manifestaram sinais de sobrecarga de estresse. Por fim, destaca-se a necessidade de analisar variáveis subjetivas de percepção do estresse e cargas de trabalho a fim de se reforçar a hipotese de que o elevado percertual de carga alostática e de padrão atípico de concentração de cortisol é de fato decorrente do estresse no trabalho. 
CONCLUSÃO 


\section{CONCLUSÃO}

O presente estudo demonstrou que mais de um quarto dos profissionais de enfermagem apresentaram padrões atípicos de secreção de cortisol do tipo "inconsistente" e "flat" e quase metade do trabalhadores manifestaram sinais subclínicos de carga alostática. Somente a idade influenciou o nível de carga alostática e não houve diferença nem na concentração de cortisol e nem na carga alostática em relação à categoria profissional e características do regime de trabalho. Além disso, o nível de carga alostática não se correlacionou com a presença de padrão atípico de secreção de cortisol. Em conjunto estes achados sugerem que a exposição crônica aos desafios do trabalho de enfermagem podem ter impacto negativo na resposta biológica do estresse, alertando sobre o risco destes profissionais em desenvolver doenças relacionadas ao estresse. 


\section{REFERÊNCIAS}

1- GazzanigaMS, Heatherton TF. Ciência psicológica: mente, cérebro e comportamento. Porto Alegre: 2007; Artmed.

2- McEwen BS, Lasley EN. O fim do estresse como nós conhecemos. Rio Janeiro: Nova Fronteira: 2003.

3- McEwen BS. Protective and damaging effects of stress mediators. Seminars in medicine of the beth israel deaconess medical center. Massachusetts. 1998; 338(3): 171-79.

4- Montanholi LL, Tavares DMS, Oliveira GR de. Estresse: fatores de risco no trabalho do enfermeiro hospitalar. Rev Bras Enferm. 2006; 59(5): 661-65.

5- Ferrareze MVG, Ferreira V, Carvalho AMP. Percepção do estresse entre enfermeiros que atuam em terapia intensiva. Acta Paul Enferm. 2006; 19(3): 310-15.

6- Kirschbaum C, Prussner JC, Stone AA, Federenko I, Gaab J, Lintz D, Schommer N, Hellhammer DH. Persistent High Cortisol Responses to Repeated Psychological Stress in A Subpopulation of Healthy-Men. Psychosom Med. 1995; 57: 468-74.

7- Ice GH, Katz-Stein A, Himes J, Kane RL. Diurnal cycles of salivary cortisol in older adults. Psychoneuroendocrinology. 2004; 29: 355-70.

8- Salomé GM, Martins MFMS, Espósito VHC. Sentimentos vivenciados pelos profissionais de enfermagem que atuam em unidade de emergência. Rev Bras Enferm. 2009; 62(6): 856-62.

9- Lyon BL. Stress, coping and health. In: Rice VH. Handbook of Stress, Coping, and Health Implications for Nursing Research, Theory, and Practice. 2nd ed. Detroit: SAGe publications; 2012..

10- Selye H The stress of life. New York: McGraw Hill 1976. 
11- Selye H. The stress concept: Past, present, and future. In: Cooper CL, EditorStress research: Issues for the eighties. New York, NY: John Wiley \& Sons; 1983. P. 1-20.

12- Mason JW. A review of psychoendocrine research on the sumpathetic adrenal medullary system. Psychosomatic Medicine. 1968; 30(5): 631-53.

13- Dickerson SS, Kemeny ME. Acute Stressors and Cortisol responses: a theorical integration and synthesis of laboratory research. Psychol bull. 2004; 130(3): 355-91.

14- McEwenBS,Mendelson S. Effects of stress on neurochemistry and morphology of the brain: Counterregulation versus damage. In: Goldberger L, Breznitz S, Editors. Handbook of stress: Theoretical and clinical aspects. 2nd ed. New York: 1993. p. 200-33.

15- Sterling P, Eyer J. Allostasis: a new paradigm to explain arousal pathology. In: Fisher S, Reason J, (Editor.). Handbook of Life Stress, Cognition and Health. New York: John Wiley \& Sons; 1988. p. 629-49).

16- McEwen BS. Physiological and neurobiology of stress and adaptation: central role of the brain. Physiol Rev. 2007; 87:873-904.

17- Diorio D, Viau V, Meaney MJ. The role of the medial prefrontal cortex (cingulate gyrus) in the regulation of hypothalamic-pituitary-adrenal responses to stress. J Neurosci. 1993; 13: $3839-47$.

18- McEwen BS, Goodman HM. Handbook of physiology. the endocrine system. Coping with the environment: neural and endocrine mechanisms. 7th ed. New York: Oxford University Press; 2001.

19- Juster RP, McEwen BS, Lupien SJ. Alostatic load biomarkers of chronic stress and impact on health and cognition. Neurosc Biobehavioral Rev. 2010; 35: 2-16.

20- Seeman TE, McEwen BS, Rowe JW, Singer BH. Allostatic load as a marker of cumulative biological risk: MacArthur studies of successful aging. Proc Natl Acad Sci. 2001; 98: 4770 .

21- Mendonça ARB de. Padrão diurno de cortisol e manifestações psicológicas do estresse em profissionais de enfermagem [dissertação]. São Paulo: Escola de Enfermagem, Universidade de São Paulo; 2014. 
22- Burke HM, Daris MC, Otte C, Mohr DC. Depression and cortisol responses to psychological stress: A meta-analysis. Psychoneuroendocrinology. 2005; 30: 846-56.

23- Stress at Work. Cincinnati, OH: U.S. National Institute for Occupational Safety and Health, DHHS (NIOSH) Publication Number 99-101.

24- American Nurses Association Health and Safety Survey Report: August. Silver Spring, MD: ANA. 2011.

25- Buerhaus PI, Donelan K, Ulrich BT,NormanL, Dittus R. State of the registered nurse workforce in the United States. Nurs Econ. 24(1): 6-13.

26- IlanMN, Durukan E, Taner E, Maral I, Bumin M A. Burnout and its correlates among nursing staff: questionnaire survey. J Adv Nurs. 2007; 61(1):100-6.

27- Piko BF. Burnout, role conflict, job satisfaction and psychosocial health among Hungarian health care staff: A questionnaire survey. Int J Nurs Stud.2006; 43; 311-18.

28- Wu S, Zhu W, WangZ, Wang M, LanY. Relationship between burnout and occupational stress among nurses in China. J Adv Nurs. 2007, 59(3), 233-39.

29- Feitosa Lima G, Simonetti SH, Bianchi ERF, Kobayashi RM. Caracterização do estresse de enfermeiros que atuam em hospital especializado em cardiologia. Enferm Glob. 2012 out; 28: $105-9$.

30- Stacciarini JM, Trócoli BT. O stress na atividade ocupacional do enfermeiro. Rev Latinoam Enferm. 2001 março-abril; 9(2):17-25.

31- Bond MA, Kajala A, MarkkanenP, CazecaD, DanielS, Tsurikova L. et al. Expanding our Understanding of the Psychosocial Work Environment: a Compendium of Measures of Discrimination, Harassment And Work-Family Issues. Cincinnati, OH: National Institute for Occupational Safety and Health, DHHS (NIOSH) Pub. No. 2008104.

32- Batista KM, Bianchi ERF. Estresse do enfermeiro em unidade de emergência. Rev Latinoam Enferm. 2006 julho-agosto; 14(4):534-9.

33- Maslach C, Jackson S. Maslach Burnout Inventiry. 2a ed. Califórnia: Manual Consulting Psychologists Press; 1986. 
34- Corrêa AK. Sendo enfermeira no centro de terapia intensiva. Rev Bras Enferm. $1995 ; 48(3): 233-4$.

35- Blegen MA. Nurses' job satisfaction: A meta-analysis of related variables. Nurs Res. $1993 ; 42 ; 36-41$.

36- HillhouseJJ, Adler CM. Investigating stress effect patterns in hospital staff nurses: Results of a cluster analysis. Soc Sci Med. 45(12): 1781-88; 1997.

37- Borda R, NormanI. Factors influencing turnover and absence of nurses: aresearch review. Inter J Nurs Stud. 1997; 34: 385-94.

38- Sancinetti TR, Soares AVN, Lima AFC, Santos NC, Melleiro MM, Fugulin FMT, Gaidzinski RR. Taxa de absenteísmo da equipe de enfermagem como indicador de gestão de pessoas. Rev Esc Enferm USP. São Paulo. 2011; 5(4): 1007-12.

39- Chiriboga DA, Bailey J.Stress and burnout among critical care and medical-surgical nurses: acomparative study. CCQ Crit Care Q. 1986;9: 84-92.

40-Metules T, Bolanger D. Nurses and suicide. The risk is real. RN, 61, 61-64.

41- Reis RJ, La Rocca PF, Silveira AM, Bonnila IML, Giné NA, Martin M. Fatores relacionados ao absenteísmo por doença em profissionais de enfermagem. Rev Saúde Pública. 2003; 37(5): 616-23.

42- Murofuse NT, Marziale MHP. Doenças do sistema osteomuscular em trabalhadores de enfermagem. Rev LatinoAm Enferm. 2005; 13(3): 364-73.

43- Rocha MCP de, Martino MFF de, Grassi-Kassisse DM, Souza AL de. Estresse em Enfermeiros: o uso do cortisol salivar no dia de trabalho e de folga. Rev Esc Enferm USP. 2013; 47(5): 1194-01.

44- Borges FNS. Trabalhadores de Enfermagem: compreendendo condições de vida e trabalho e ritmos biológicos [tese na internet]. São Paulo (Brasil): Universidade de São Paulo, Faculdade de Saúde Pública; 2007 [citado 27 abr 20015]. Disponível em: file:///C:/Users/cloliveira/Downloads/Borges_FNS.pdf. 
45- Ulhôa MA. Fatores psicossociais no trabalho e cortisol: breve revisão. São Paulo, 2011 [citado abr 2015]. Disponível em: http://www.revistas.sp.senac.br/index.php/ITF/article/viewFile/49/78..

46- Dalri RCMB. Carga horária de trabalho dos enfermeiros de emergência e sua relação com estresse e cortisol salivar [tese]. São Paulo: Universidade de São Paulo, Escola de enfermagem; 2013.

47- Lupien SJ. How to measure stress in humans. Second Edition Center of Study on Human Stress. Canada, 2013.

48- Juster RP, Sindi S, Marin MF, Perna A, Hashemi A, Pruessner JC, Lupien SJA. Clinical allostatic load index is associated with burnout symptoms and hypocortisolemic profiles in healthy workers. Psychoneuroendocrinology. 2001; 36:797-805.

49- Kudielka BM, Broderick JE, Kirschbaum C. Compliance with saliva sampling protocols: eletronic monitoring reveals invalid cortsiol daytime profiles in noncompliant subjects. PsychosomMed. 2003; 65: 313-9.

50- Pruessner J. C, Kirschbaum C, Meinlschmid G., Hellhammer DH. Two formulas for computation of the area under the curve represent measures of total hormone concentration versus time-dependent change. Psychoneuroendocrinology. 2003;28(7): 916-31.

51- Conselho Federal de Enfermagem. [citado 21 abr. 2015]. Disponível em: www.cofen.gov.br.

52- Instituto de Pesquisa Aplicada (IPEA). Ranking traz ocupações com os maiores salaries [citado 21 abr. 2015]. Disponível em: http://www.ipea.gov.br/portal/index.php?option=com_content\&view=article\&id.

53- Teixeira RC. Mantovani MF. Enfermeiros com doença crônica: as relações com o adoecimento, a prevenção e o processo de trabalho. Rev esc enferm USP. 2009; 43(2):415-21.

54- Souza-Talarico JN. Estresse, concentrações de cortisol e estratégias de coping no desempenho da memória de idosos saudáveis, com comprometimento cognitivo leve e doença de Alzheimer [doutorado]. São Paulo (SP): Escola de Enfermagem, Universidade de São Paulo; 2009. 
55- Morgan Ca, Cho T, Hazlett G, Coric V, Morgan J. The impact of burnout on human psysiology and on operational performance; a prospective study of soldiers enrolled in the combat diver qualification course. Yale J Biol Med. 2002; 75: 199 - 205.

56- Smyth j, Ockenfels, M, Gorin A, Catley D, Porter L, Kirschbaum C, Hellhammer D, Stone A,Individual differences in the diurnal cycle of cortisol. Psychoneuroendocrinology. 1997; 22: 89-105.

57- Fiocco AAJ, Wan N, Weekes N, Pim H, Lupien SJ. Diurnal cycle of salivary cortisol in older adult men and women with subjective complaints of memory deficits and/or depressive symptoms: relation to cognitive functioning. UK Informa 2006; 9(3): 143-52.

58- Wust S, Wolf J, Hellhammer D, Federenko I, Schommer N, Kirschbaum C. The cortisol awakening response - normal values and confounds. Noise Health. 2000; 2 (7): 79-88.

59- Pruessner JC, Wolf OT, Hellhammer DH, Buske-Kirschbaum A, Von Auer K, Jobst, S, Kaspers F, Kirschbaum C.. Free cortisol levels after awakening: a reliable biological marker for the assessment of adrenocortical activity. Life Sci. 1997; 61: 2539-49.

60- Steptoe A, Cortisol awakening response. In: Fink G, editor Encyclopedia of Stress, 2nd ed. Oxford: Academic Press; , p649-53.

61- Clow A, Thorn L, Evans P, Hucklebridge F. The awakening cortisol responsa: methodological issues and significance. Stress. 2004; 7: 29-37.

62- CamposJF, David HMSL. Analysis of salivary cortisol as stress biomarker in nursing workres. Rev enferm UERJ.. 2014 jul/ago; 22(4): 447-53.

63- Kunz-Ebrecht SR, Kirschbaum C, Steptoe A. Work stress, socio-economic status neuroendocrine activation over the working day.Soc Sic Med. 2004; 58: 1523-30.

64- Steptoe A, Cropley M, Griffith J, Kirschbaum C. Job strain and anger expression predict early morning elevations in salivary cortisol. Psychosom Med. 2000; 62: 286-92.

65- Evolahti A, Hultcrantz M, Collins A. Women`s work stress and cortisol levels: longitudinal study of the association between the psychosocial work environment and serum cortisol. J Psychosom Res. 2006; 61: 645-52. 
66- Ganster DC, Fox ML, Dwyer DJ. Explaining employees`health care costs: a prospective examination of stressful job demands, personal control, and physiological reactivity. J Appl Psychol. 2001. 86(5): 954-64.

67- Yang Y, Koh D, Ng V, Lee FC, Chan G, Dong F, Chia SE. Salivary cortisol levels and work-related stress among emergency departmaent nurses. J Occup Environ Med. 2001; 43 (12): 1011-8.

68- GeissA, Varadi E, Steinbach K, Bauer HW, Anton F, Psychoneuroimmunological correlates of persisting sciatic pain in patients who underwent discectomy. Neurosci Lett. 1997; 237: 65-68.

69- Healy CM, Mckay MF. Nursing stress : the effects of coping strategies and job satisfaction in a sample of Australian nurse. J adv Nurs. 2000; 31(3): 681 - 8.

70- Gurgueira GP, Alexandre NMC, Corrêa HR Filho. Self-reported musculoskeletal sympotoms among nursing personnel. RevLatAmEnfermagem. 2009; 6:11-5

71- Miniel VA. Promoção da qualidade de vida dos trabalhadores de enfermagem: Responsabilidade gerencial do enfermeiro [dissertação]. São Paulo (SP): Escola de Enfermagem - Universidade de São Paulo: 2006.

72- Miniel VA, Baptista PCP, Felli VEA. Psychic Workloads and Strain Processes in Nursing Workers of Brazilian University Hospitals. Rev. Lat. Am-Enfermagem;19(2): 9

73- Kuper H, Marmot M. Job satrain, job demands, decision latitude, and risk of coronary heart disease within the Whitehall II study. J Epidemiol Community Health. 2003; 57: 14753.

74- Sancinetti TR, Gaidzinski RR, Felli VEA, Fugulin FMT, Baptista PCP, Ciampone MHT, Kurcgant P, Silva FJ Absenteísmo - doença na equipe de enfermagem: relação com a taxa de ocupação. Rev Esc Enferm USP. 2009; 43(2):1277-83.

75- Arimura M, Imai M, Okawa M, Fujimura T, Yamada N. Sleep, mental health status, and medical errors among hospital nurses in japan. Ind Health. 2010; 4848(6):811-7.

76- KudielkaBM, Kirschbaum C. Sex differences in HPA axis responses to stress: a review. Biol Psychol. 2005;69:113- 32. 
77- GotthardtU, SchweignerU, Fahrenberg J, Lauer CJ, Holsboer F, Heuser.I Cortisol, ACTH and cardiovascular response to a cognitive challenge paradigm in again and depression. Am. J. Physiol. 1995; 268: R865-873.

78- KudielkaBM, Scmidt-Reinwald AK, Hellhammer DH, Kirshbaum C. Psychosocialstress and functioning of the hypothalamic-pituitary-adrenal axis: no evidence for a reduced resilicence in elderly men. Stress. 2000; 3(3); 229-40.

79- Bellingrath S, Weigl T, Kudielka BM. Chronic work stress and exhaustion is associated with higher allostastic load in female school teachers. Stress. 2009; $12 ; 37-48$.

80- Li W, Zhang JQ, Sun J, Ke JH, Dong ZY, Wang S. Job stress related to glyco-lipid allostatic load, adiponectin and visfatin. Stress Health. 2007; 23:257-66.

81- Kinnunen MJ., KaprioJ, Pulkkinen L, Allostatic load of men and woen in early middle age. JInd Diff. 2005; 26: $20-8$.

82- Sun J, Wang S, Zhang JQ,Li W. Assessing the cumulative effects of stress: the association between job stress and allostatic load in a large sample of Chinese employees. Work Stress. 2007;21: 333—47.

83- Von ThieleU, Lindfors P, Lundberg U.. Self-rated recovery from work stress and allostatic load in women. J Psychosom Res. 2006; 61: 237—42.

84- Schnorpfeil P, Noll A, Schulze R, Ehlert U, Frey K, Fischer JE.. Allostatic load and work conditions. Soc Sci Med. 2003; 57:647-56.

85- Abbott DH, Keverne EB, Bercovitch FB, Shively CA, Mendoza SP, Saltzman W, Snowdon CT, Ziegler TE, Banjevic M, Garland T,Sapolsky RM. Are subordinates always stressed? a comparative analysis of rank differences in cortisol levels among primates. Horm Behav.2003; 43: 67e82.

86- Sapolsky RM. Endocrinology of the stress response. In: Behavioral Endocrinology. 2nd ed. Cambridge: Massachusetts; MIT Press, 2002.

87- Miranda AF. Estresse ocupacional: inimigo invisível do enfermeiro? [Dissertação] Ribeirão Preto(SP):Escola de Enfermagem de Ribeirão Preto/USP; 1998. 
88- Panizzon C, Luz AMH, Fensterseifer LM. Estresse da equipe de enfermagem de emergência clínica. Rev Gaúcha Enferm. 2008; 29 (3): 391-9.

89- Menzani G, Bianchi ERF. Stress dos enfermeiros de pronto socorro dos hospitais brasileiros. Rev Eletrônica Enferm. 2009; 11(2): 327-33.

90- Schimidt DRC, Dantas ARS, Marziale MHP. Ansiedade e depressão entre profissionais de enfermagem que atuam em blocos cirúrgicos. Rev Esc Enferm USP. 2011; 45(2): 487-93.

91- Silva JLL, Melo ECP, Griep RH, Rotemberg L. Estresse, Trabalho e Ambiente: prevalência de transtornos mentais comuns entre trabalhadores de enfermagem de um hospital federal de um município do rio de janeiro [citado 15 abr 2015]. Disponível em: http://www.uff.br/anaissegerenf/premio/texto\%20uff.semana.pdf.

92- Gouveia MTO. Estresse e jornada laboral dos trabalhadores de enfermagem. [Doutorado]. Escola de Enfermagem da USP Ribeirão Preto, 2015.

93-Beck CLC, Stekel LMC, Gonzales RMB, Donaduzzi JC. Nursing work in critical units and its repercussion over worker`s health. Esc Anna Nery R Enferm. 2006; 10 (2):221-7.

94- Fischer JE, Calame MS, Dettling AC, Hans Z, Fanconi S. Experience and endocrine stress response in neonatal and pediatric critical nurses and physycians. Ped Crit Care. 2000; 28(9): 3281-88.

95- Metzenthin P, Helfricht S, Loerbroks A, Terris DD, Haug HJ, Subramanian SV, Fischer JE. A one-item subjective work stress assessment tool is associated with cortisol secretion levels in critical care nurses. Prev Med. 2009; 48(5):462-6.

96- Wingenfeld K, Schulz M, Damkroeger A, Rose M, Driessen M. Elevated diurnal salivary cortisol in nurses is associated with burnout but not with vital exhaustion. Psychoneuroendocrinology. 2009; 34(8):1144-51. 
ANEXO 


\title{
ANEXOS
}

\author{
ANEXO A - TERMO DE CONSENTIMENTO LIVRE E ESCLARECIDO \\ AVALIAÇÃO DE BIOMARCADORES DE ESTRESSE CRÔNICO EM PROFISSIONAIS \\ DE ENFERMAGEM
}

Prezado senhor (a):

O Departamento de Enfermagem Médico-Cirúrgica da Escola de Enfermagem da Universidade de São Paulo (EE-USP) está desenvolvendo um estudo transversal sob a coordenação da Profa. Dra. Juliana Nery de Souza Talarico com o objetivo de avaliar o estresse crônico de profissionais de enfermagem atuantes em unidades hospitalares. Para isso pedimos sua autorização para incluí-lo no grupo de estudo, solicitando que responda a alguns questionários e testes para avaliar seu estresse, bem como coleta de saliva e sangue para avaliar sua resposta ao estresse.

Inicialmente, o $\operatorname{Sr}(\mathrm{a})$ responderá a questionários de identificação pessoal, de estresse e de depressão, sendo posteriormente necessária a coleta de saliva para analisar a dosagem de cortisol em seu corpo, um hormônio relacionado ao estresse e coleta de sangue para avaliar os efeitos do estresse em seu organismo. Para coletar a saliva será necessário que o $\operatorname{Sr}(\mathrm{a})$ mastigue um pedaço de algodão por aproximadamente 03 minutos.

Esclarecemos que a data e horário para realização de todos os procedimentos mencionados serão previamente agendados de acordo com sua disponibilidade e conveniência.

Embora os procedimentos de coleta de saliva e sangue representem risco mínimo à sua saúde e bem-estar, ressaltamos que caso surja algum desconforto ao longo de sua participação no estudo o sr(a) poderá retirar seu consentimento de participação a qualquer momento sem que haja prejuízo ao $\operatorname{sr}(\mathrm{a})$. Esclarecemos que os possíveis riscos relacionados à punção venosa para coleta de sangue incluem complicações locais como hematoma, flebite (inflamação da parede do vaso sanguíneo) e infecção local, além de, mais raramente, complicações infecciosas sistêmicas.

Esclarecemos que não há benefício direto ao participante do estudo, uma vez que se trata de um estudo exploratório investigando o padrão de resposta de estresse. Assim, somente ao final do estudo poderemos concluir como está seu nível de estresse. Entretanto, a partir desta avaliação poderá ser informado os resultados obtidos com as amostras de saliva e sangue do $\operatorname{Sr}(\mathrm{a})$.

Ademais, garantimos ao senhor acesso, em qualquer etapa do estudo, à equipe de pesquisa (Enfermeiras Siomara Tavares Fernandes Yamaguti e Amanda Roca Blasques de Mendonça) e ao pesquisador responsável (Profa. Dra. Juliana Nery de Souza Talarico), que pode ser encontrada na Av. Dr Enéas de Carvalho Aguiar, n. 419, telefone (11) 30617544. Se você tiver alguma consideração ou dúvida sobre a ética da pesquisa, entre em contato com o Comitê de Ética em Pesquisa da EE-USP (CEP- EEUSP) no mesmo endereço mencionado anteriormente, no telefone (11) 3061-7548 ou pelo e-mail: edipesq@usp.br ou no Comitê de Ética em Pesquisa do Hospital Universitário da USP no endereço: Av. Prof. Lineu Prestes, 2565 - Cidade Universitária - CEP: 05508-000 - São Paulo - SP - Telefone: 3091-9457 Fax: 3091-9452 - E-mail: cep@hu.usp.br 
É garantida a liberdade da retirada de consentimento a qualquer momento e deixar de participar do estudo, sem qualquer prejuízo à continuidade de seu tratamento na Instituição. Além disso, todas as informações obtidas serão analisadas em conjunto com as de outros voluntários, não sendo divulgada a identificação de nenhum pesquisado.

O Sr(a) tem o direito de ser mantido atualizado sobre os resultados parciais da pesquisa que sejam de conhecimento dos pesquisadores. Ressaltamos que não haverá despesas pessoais para o $\operatorname{sr}(a)$ em qualquer fase do estudo. Também não haverá compensação financeira relacionada à sua participação. Se existir qualquer despesa adicional, ela será absorvida pelo orçamento da pesquisa. Caso seja detectada alguma alteração nas avaliações realizadas, como alteração na pressão arterial, exames de sangue e questionário de investigação de depressão (Escala de Depressão de Beck) o sr(a) será encaminhado ao ambulatório do Hospital Universitário para avaliação médica. Assim como em caso de dano pessoal, diretamente causado pelos procedimentos propostos neste estudo, com nexo causal comprovado, o sr(a) tem direito a tratamento médico na Instituição, bem como às indenizações legalmente estabelecidas. Ademais, o pesquisador responsável se compromete a utilizar os dados e o material coletado somente para esta pesquisa.

Cabe informar que este termo de consentimento foi elaborado em 2 (duas) vias e que uma delas ficará com o $\operatorname{Sr}(a)$ e outra com o pesquisador responsável.

Acredito ter sido suficientemente informado a respeito das informações que li ou que foram lidas para mim, descrevendo o estudo "Avaliação de biomarcadores de estresse crônico em profissionais de enfermagem".

Eu discuti com a Mestranda Siomara Tavares Fernandes Yamaguti sobre a minha decisão em participar nesse estudo. Ficaram claros para mim quais são os propósitos do estudo, os procedimentos a serem realizados, seus desconfortos e riscos, as garantias de confidencialidade e de esclarecimentos permanentes. Ficou claro também que minha participação é isenta de despesas e que tenho garantia do acesso a tratamento hospitalar quando necessário. Concordo voluntariamente em participar deste estudo e poderei retirar o meu consentimento a qualquer momento, antes ou durante o mesmo o processo.

Data: I

RG n.

Assinatura do pesquisado:

Data: I

RG n.

Assinatura da testemunha:

Declaro que obtive de forma apropriada e voluntária o Consentimento Livre e Esclarecido deste pesquisado ou representante legal para a participação neste estudo.

Data: 1

RG n.

Assinatura do responsável pelo estudo: 


\section{ANEXO B - QUESTIONÁRIO SÓCIO-DEMOGRÁFICO DE IDENTIFICAÇÃO}

\section{Setor:}

( ) Ambulatório
( )Clínica Cirúrgica
( )Pediatria
( )UTI-Infantil

( )Clinica Médica,

( )Centro Cirúrgico

( )UTIAdulto

( )PS Adulto ( )PSInfantil ( ) Outros

Nome:

Data de Nascimento: Sexo: Idade:

Estado civil: ( ) solteiro $\overline{(\text { ) casado ( ) divorciado ( ) outro }}$

Naturalidade: Nacionalidade:

Endereço:

Cidade: Telefone: Bairro:

Quanto tempo leva entre casa e HU? Celular:

Anos de estudo:

Carga horária semanal: Turno: ( ) manhã

( ) tarde

Trabalha em outra instituição além do HU? ( ) sim ( ) não

Se sim, Quantas horas semanais? Em qual turno? ( ) manhã ( ) tarde

Tempo de trabalho na profissão:

Tempo de trabalho no HU:

Voltou de férias recentemente? ( ) sim ( ) não Há quanto tempo?

Uso de medicações nos últimos três meses (nome, dose por dia):

Tabagismo: ( ) sim ( ) não Quanto/ há quanto tempo:

Alcoolismo: ( ) sim ( ) não Quanto/ há quanto tempo:

Reposição Hormonal: ( ) sim ( ) não Quanto tempo:

\section{CICLO MENSTRUAL}

Data da última menstruação

Faz uso de anticoncepcional ( ) sim ( ) não Qual?

Se não, o ciclo menstrual é, em média, de quantos dias (26, 28, 30 etc)?

\section{ANTECEDENTES PESSOAIS}
Diabetes
0-Não 1-Sim
Hipertensão arterial 0 -Não 1-Sim
AVC:
0-Não 1-Sim, quantas vezes: $\bullet 1 \cdot 2 \cdot 3 \cdot 4-5$
Infarto/Angina:
0-Não 1-Sim

Outros antecedentes:

Pressão Arterial 2: $\mathrm{mmHg}$

Peso: Altura: IMC:

Circunferência abdominal: Cintura: Quadril: Razão cintura quadril: 
Posse de itens

\begin{tabular}{|c|c|c|c|c|c|}
\hline & \multicolumn{5}{|c|}{ Quantidade de Itens } \\
\hline & 0 & 1 & 2 & 3 & 4 ou + \\
\hline Televisão em cores & 0 & 1 & 2 & 3 & 4 \\
\hline Rádio & 0 & 1 & 2 & 3 & 4 \\
\hline Banheiro & 0 & 4 & 5 & 6 & 7 \\
\hline Automóvel & 0 & 4 & 7 & 9 & 9 \\
\hline Empregada mensalista & 0 & 3 & 4 & 4 & 4 \\
\hline Máquina de lavar & 0 & 2 & 2 & 2 & 2 \\
\hline Videocassete e/ou DVD & 0 & 2 & 2 & 2 & 2 \\
\hline Geladeira & 0 & 4 & 4 & 4 & 4 \\
\hline Freezer (aparelho independente ou parte da geladeira duplex) & 0 & 2 & 2 & 2 & 2 \\
\hline
\end{tabular}

\section{Grau de Instrução do chefe de família}

\begin{tabular}{|ll|}
\hline \multicolumn{1}{|c|}{ Nomenclatura Antiga } & \multicolumn{1}{c|}{ Nomenclatura Atual } \\
\hline Analfabeto/ Primário incompleto & Analfabeto/ Fundamental 1 Incompleto \\
\hline Primário completo/ Ginasial incompleto & Fundamental 1 Completo / Fundamental 2 Incompleto \\
\hline Ginasial completo/ Colegial incompleto & Fundamental 2 Completo/ Médio Incompleto \\
\hline Colegial completo/ Superior incompleto & Médio Completo/ Superior Incompleto \\
\hline Superior completo & Superior Completo \\
\hline
\end{tabular}

Renda mensal familiar: $\mathrm{R} \$$

Quantas pessoas vivem com a renda: 


\title{
ANEXO C - ORIENTAÇÕES PARA A COLETA DE SALIVA
}

\author{
Identificação:
}

\section{ORIENTAÇÕES PARA A COLETA DE SALIVA}

O senhor está recebendo dois frasquinhos marcados "1음 DIA" e " 20 DIA".

Em cada um destes frascos existem 05 tubinhos para colher saliva.

A saliva deve ser colhida no 1 을 DIA e no 2 ㅇ DIA

Em cada dia o senhor deverá colher:

- 01 amostra de saliva imediatamente ao acordar.

- 01 amostra de saliva 30 minutos após acordar.

- 01 amostra de saliva às $14 \mathrm{~h}$.

- 01 amostra de saliva às $16 \mathrm{~h}$.

- 01 amostra de saliva antes de dormir.

Nos dois dias da coleta de saliva o senhor NÃO pode praticar nenhum exercício físico. 60 minutos antes de colher as amostras de saliva o senhor(a):

- NÃO pode escovar os dentes

- NÃO pode fumar

- NÃO pode ingerir qualquer alimento ou bebida.

\section{DIA}

Horário em que acordou h

- Pegue o frasco branco Dia 1

- Retire o salivette escrito "AO ACORDAR"

- Retire o algodão de dentro do salivette

- Mastigue o algodão por aproximadamente 03 minutos.

- Coloque o algodão molhado de saliva novamente salivette.

- Anote aqui o horário da coleta: $h$

- COLOQUE O SALIVETTE NA GELADEIRA (NÃO colocar no congelador)

- Responda as seguintes perguntas: Você comeu alguma coisa nos últimos 60 minutos? ( ) sim （）não Você fumou nos últimos 60 minutos? ( ) sim ( ) não Você bebeu alguma bebida alcoólica nos últimos 60 minutos? ( ) sim ( ) não Você tomou alguma medicação ou vitamina nos últimos 60 minutos? ( ) sim ( ) não Como foi seu sono esta noite?
( ) Muito bom
( ) Bom
( ) Ruim
( ) Muito ruim

30 minutos após, repita o procedimento com o salivette “30 min. APós ACORDAR”

- Anote aqui o horário da coleta: $\mathrm{h}$

- COLOQUE O SALIVETTE NA GELADEIRA (NÃO colocar no congelador).

\section{às $14 \mathrm{~h}$ repita o procedimento com o salivette "14H"}

- Anote aqui o horário da coleta: $h$

- COLOQUE O SALIVETTE NA GELADEIRA (NÃO colocar no congelador).

\section{às $16 \mathrm{~h}$ repita o procedimento com o salivette " $16 \mathrm{H}$ "}

- Anote aqui o horário da coleta: $\mathrm{h}$ 
- COLOQUE O SALIVETTE NA GELADEIRA (NÃO colocar no congelador).

Antes de dormir repita o procedimento com o salivette "AO DORMIR".

- Anote aqui o horário da coleta: ___ _ _

- COLOQUE O SALIVETTE NA GELADEIRA (NÃO colocar no congelador).

\section{FACA O MESMO NO 2으모}

20 DIA

_Horário em que acordou__ :

- Pegue o frasco branco Dia 2

- Retire o salivette escrito "AO ACORDAR"

- Retire o algodão de dentro do salivette

- Mastigue o algodão por aproximadamente 03 minutos.

- Coloque o algodão molhado de saliva novamente salivette.

- Anote aqui o horário da coleta: $h$

- COlOQUE O SAlivetTE NA GELADEIRA (NÃO colocar no congelador)

- Responda as seguintes perguntas:

Você comeu alguma coisa nos últimos 60 minutos? ( ) sim ( ) não

Você fumou nos últimos 60 minutos? ( ) sim ( ) não

Você bebeu alguma bebida alcoólica nos últimos 60 minutos? ( ) sim ( ) não

Você tomou alguma medicação ou vitamina nos últimos 60 minutos? ( ) sim ( ) não

Como foi seu sono esta noite?

( ) Muito bom

( ) Bom

( ) Ruim

( ) Muito ruim

30 minutos após, repita o procedimento com o salivette "30 min. APÓs ACORDAR"

- Anote aqui o horário da coleta: $h$

- COlOQUE O SALIVETTE NA GELADEIRA (NÃO colocar no congelador).

\section{às $14 \mathrm{~h}$ repita o procedimento com o salivette "14H"}

- Anote aqui o horário da coleta: $h$

- COLOQUE O SALIVETTE NA GELADEIRA (NÃO colocar no congelador).

\section{às $16 \mathrm{~h}$ repita o procedimento com o salivette " $16 \mathrm{H}$ "}

- Anote aqui o horário da coleta: h

- COLOQUE O SALIVETTE NA GELADEIRA (NÃO colocar no congelador).

Antes de dormir repita o procedimento com o salivette "AO DORMIR".

- Anote aqui o horário da coleta: h

- COLOQUE O SALIVETTE NA GELADEIRA (NÃO colocar no congelador).

Mantenha os tubos na geladeira até a data de retorno no dia

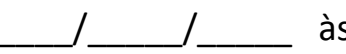
às h. NÃO colocar no congelador.

Trazer os tubos com saliva dentro da caixa de isopor com gelo.

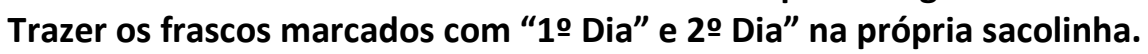

Se tiver alguma dúvida, por favor, ligue-me: SIOMARA (11) 97649-6388, AMANDA (13) 991015766, DANIELA (11) 96366-7222 
APEETNDICE 


\section{APÊNDICE A}

\section{ESCOLA DE ENFERMAGEM DA \\ UNIVERSIDADE DE SÅO \\ PAULO - EEUSP}

\section{PARECER CONSUBSTANCIADO DO CEP}

\section{DADOS DO PROJETO DE PESQUISA}

Thtulo da Peequisa: Avalispato de biomarcadorea de estresse crónico em profissionaia de entormagom

Pesquisador: Julana Nory do Souza Talarico

Área Temb́tica:

Verabo: 3

CAAE: 13401513.000005392

Instituighto Proponente: Escola de Entormagom da Univorzidade de Sso Paulo - EEUSP

Patrocinador Principal: FUNDACAO DE AMPARO A PESOUISA DO ESTADO DE SAO PAULO

\section{DADOS DO PARECER}

Número do Parecer: 403.390

Data da Relatorla: $170 a{ }^{20} 13$

Apresentaçdo do Projeto:

O projoto Avaliagso de biomarcadores de cetresse crónice em protsasionala de entormagem fol aprovado por este CEP, tendo o parecer consubatanciado sido emitido om 7/8/2013. Fol reencaminhado para que pudeasom sor agrogadas reapostas a pondincias sinalzadas polo CEP do Hoapital Univorsithrib da USP. insthulghto co-participanto.

Objetivo da Pesquisa:

Avalier a frequđincia de profissionais de enfarmagom sob estrosen crónice, bem como sua relaçso com

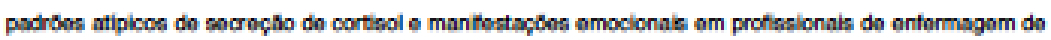
unidades hoaptalares.

Avalleçdo dos Riscos e Beneficios:

Considerou os riecoe de descontorto soe procodimentos de coleta de saliva, punçso vencesa e entreviata. portm, avaliou que sto minimoa.

Comentarios e Considerapoles sobre a Pesqulas:

A peequisa, que protende avalior a froquência do profissionaia de entormagom sob ostrosse crónico o sua


medisdores biolbgicos o do padrso diurno de cortisol. As manifostaposes emocionais do estresse seráo avaliadas a partir do inatrumentos peicombitricos de perceppso de






\section{ESCOLA DE ENFERMAGEM DA \\ UNIVERSIDADE DE SÅO \\ PAULO - EEUSP}

Cothacklo do Punor: waset

cetrosen o dopreesso.

Consideraçóes sobre os Termos de apresentap̧to obrigatoria:

Oe tormes soguem as recomendoples da rosoluphito 466, de 2012.

\section{Recomendapobea:}

Nso ht.

Conclusobea ou Pendéncias e Lista de Inadequaçoes:

O projoto fol aprovado antoriormento.

Situaçbo do Parecer:

Aprovindo

Necesaita A preciaçio da CONEP:

NSo

Consideraçఠes Finais a criterilo do CEP:

Esto CEP considerou o projoto aprovado do ponto de viata btico para a continuidade do processo de pesquisa. No entanto, esta aprovaçso nso subathui a autorizachlo da institulghto co-participarto. proviamerto $\infty$ iniclo da pesquisa.

Roltarase a necesaidade de registro doe reeutsodos pardais o finais da pesquisa, na Plataforma Brasl.

SNO PAULO, 23 de Setmmbro de 2013

Assinador por:

Cella Maria Sivalli Campos

(Coordenador)

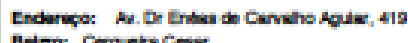

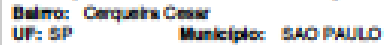

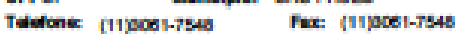

E-mall: odpexpatapbr

$\operatorname{man} 2 \pi$ 


\section{HOSPITAL UNIVERSITÁRIO DA UNIVERSIDADE DE SÅO PAULO - HU/USP}

\section{PARECER CONSUBSTANCIADO DO CEP}

Elaborado pela Instituiçálo Coparticlpante

\section{DADOS DO PROJETO DE PESCUISA}

Thulo da Peequisa: Avalispato de biomarcadorea de estresse crónico em profissionais de entormagom

Pesquiseder: Julana Nory de Souza Talarico

Área Tembitica:

Verabio: 3

CAAE: 13401513.800005392

Instituighto Proponente: Escola de Entermagom da Univorridade de Sso Paulo = EEUSP

Patrocinador Principal: FUNDACAO DE AMPARO A PESOUISA DO ESTADO DE SAO PAULO

\section{DADOS DO PARECER}

Número do Parecer: 415,966

Data da Relatoria: 271092013

Apresentaçdo do Projeto:

Estudo traneversal com aplicaplo de questiontrios de avaliaplo do estreseo e depresesto, bem como coleta do matarial biolbgico (sangue e saliva) para avaliap̧a doe biomarcadores de eatrosse crónico. Serâo incluldos no estudo 189 profisaionale de entermagom (audilares, thonicos, enformoiroe), do ambos os saxces - fabea octria, do turno diurno de trabalho, atuantes nas unidados de Ambulatorio, Clinica Modica. Clinica Crúrgica, Centro Cirúrgico, Contro Obethtrico, Podiatria, Berphrio, Unidade de Terapia Intenaiva Adulto o Intantl o Unidsobe de Pronto Atendimento Adubo e Infantil. A salva sert colotada no domicllo e o sangue sera colotado no hospital, quando serb tambem realizada medida da prossto arterial e medidas antropombtricas. Alam da colota do matorial biobgica, os profisalonala respondorło a queationarios do

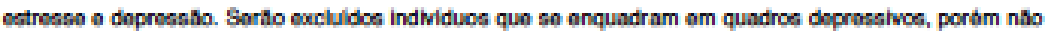
peesuem disgntetico clínico da patologia.

\section{Objethro da Peequias:}


rolaçso com padroses atipicos de socreçato de cortisol a mantostaptes emocionais om profissionaia do entarmsoom do unidades hosptalares.



$$
\begin{aligned}
& \text { Endarwo: Au. Prof Lune Mresten, ases }
\end{aligned}
$$

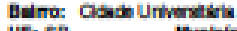

$$
\begin{aligned}
& \text { UF: SP Wunkiploc saopauL } \\
& \text { Cep: } 08.506000
\end{aligned}
$$



E-mal: copatuseser 


\section{HOSPITAL UNIVERSITÁRIO DA UNIVERSIDADE DE SÅO PAULO - HU/USP}

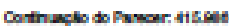

crónica, a portir dos indicsdores biolbgicos de sobrecarga alostabica e manifostagbes emocionaia; identifosr

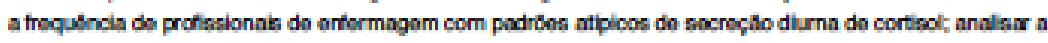
rolaçbo entro sobrocarga alostatica e padrbes atipicce do secroptb diurna de cortibol; analianr a relaptso ontro indicadorns biolbgicos do sobrocarga alostibica e mantbestapbes emocionais do estresse; comparar a sobrecarga alostatica e podross atiplicos de secrecito diurna de cortieol entre profissionais alocados nas diforentos unidados hoapitalarna.

\section{Avalleçto dos Riscos e Beneficios:}

O autor conaidora risco minimo, sera realzado questiontrio do stross o doprossto, colotado saliva atravbes

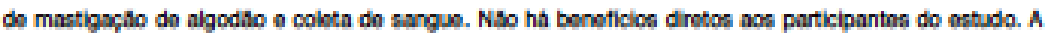
investigaçio sobre de que maneira o desgaste fisice e emocional dos trabalhadores se expressa no tuncionamento do organiamo pode contribur para a avaliaça do risco de adoocimento a que está expostos

Comentarios e Considerapoes sobre a Pesqulaa:

Pasquisa robvante, bem delineada, com motodologla sdoqusda com financiomento FAPESP.Este projpto fol aprovado polo Comits do Etica om Posquisa da EEUSP.

Considerą̧চbes sobre os Termos de apresentap̧io obrigatoria:

TCLE aprosentado adoquado.

Recomendap̧6es:

NSo ha

Conclusces ou Pendíncias e Lista de Inadequaçoes:

Sou pola aprovaçio do projoto

Situaçbo do Parecer:

Aprovado

Necessita Aprecioplio da CONEP

NSo

Considerạ̧óses Finais a crittrílo do CEP:

Apbe rouniso este comins coneiderou o presento projoto aprovado.

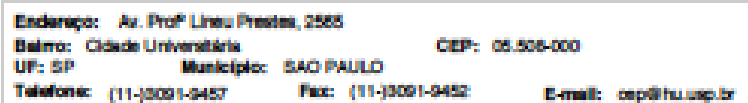




\section{APÊNDICE B}

Tabela 8: Valores de referência dos biomarcadores analisados com unidades do sistema nacional e sistema internacional e os respectivos valores de conversão.

\begin{tabular}{|c|c|c|c|}
\hline Biomarcadores & $\begin{array}{c}\text { Valores de } \\
\text { referência }(\mathrm{SN})\end{array}$ & $\begin{array}{l}\text { Fator de } \\
\text { conversão }\end{array}$ & $\begin{array}{c}\text { Valores de } \\
\text { referência (SI) }\end{array}$ \\
\hline Fibrinogênio $\mathrm{g} / \mathrm{L}$ & $175-400 \mathrm{mg} / \mathrm{dl}$ & 0,01 & $1,8-4,0$ \\
\hline Proteína $\mathrm{C}$ reativa $\mathrm{nmol} / \mathrm{L}$ & Inferior a $3 \mathrm{mg} / \mathrm{l}$ & 9.524 & 28,57 \\
\hline Hemoglobina glicada (\%) & $<5,7 \%$ & 0,01 & $0,0460-0,0620$ \\
\hline DHEA-S nmol/L & $\begin{array}{l}\text { Masculino } 35-569 \mathrm{mcg} / \mathrm{dL} \\
\text { Feminino } 26-460 \mathrm{mcg} / \mathrm{dL}\end{array}$ & 0,027 & $\begin{array}{l}\text { Masculino 0,94-15,36 } \\
\text { Feminino 0,070-12,42 }\end{array}$ \\
\hline Cortisol plasmático nmol/L & $4.3-22.4 \mathrm{mcg} / \mathrm{dL}$ & 27,59 & $118,63-618,01$ \\
\hline Colesterol total $\mathrm{mmol} / \mathrm{L}$ & $<200 \mathrm{mg} / \mathrm{dl}$ & 0,0259 & $<5,17$ \\
\hline HDL colesterol nmol/L & $>60 \mathrm{mg} / \mathrm{dL}$ & 0,0259 & $>1,55$ \\
\hline
\end{tabular}

